\title{
The role of extracellular vesicles in rheumatoid arthritis: a systematic review
}

\author{
Tommaso Schioppo ${ }^{1,2}$ (D) Tania Ubiali $^{1}$ (D) $\cdot$ Francesca Ingegnoli ${ }^{1,2}$ (D) $\cdot$ Valentina Bollati $^{2,3}$ (D) Roberto Caporali $^{1,2}$ (I)
}

Received: 10 November 2020 / Revised: 7 January 2021 / Accepted: 25 January 2021 / Published online: 5 February 2021

(C) The Author(s) 2021

\begin{abstract}
Rheumatoid arthritis (RA) is a chronic inflammatory disease that carries high social and economic costs and can lead to permanent disability. RA pathogenesis has not been completely elucidated yet. Extracellular vesicles (EVs) are membrane-contained vesicles released by cells playing a role in cell-to-cell communication and they could be involved in different diseases. Evidence on the involvement of EVs in RA is currently inconclusive. Therefore, a systematic review on the role of EVs in RA was performed in order to explore this relationship. This review followed the Preferred Reporting Items for Systematic Reviews and Meta-Analyses (PRISMA) guidelines. The research was conducted on PubMed, Scopus, and Embase up to March 5, 2020: 41 studies were analyzed out of 674 screened. The total plasmatic and synovial fluid (SF) EV number seems increased in RA as compared with healthy controls. Both RA plasma and SF contained EVs subpopulations of heterogenous origin, especially derived from platelets and immune system cells. No univocal evidence emerged on miRNA expression and EV content profile within RA patients. EVs showed to enhance pro-inflammatory pathways, such as cytokines and chemokine release and TNF blockade seemed to revert this effect. Our work highlights the requirement to standardize study methodologies in order to make results comparable and draw conclusions that remain, at present, unclear.
\end{abstract}

Keywords Exosomes $\cdot$ Extracellular vesicles $\cdot$ Microvesicles $\cdot$ Rheumatoid arthritis

\section{Introduction}

Rheumatoid arthritis (RA) is a chronic inflammatory autoimmune disease with a considerably high social and economic impact. RA can result in loss of function, permanent disability, and severe systemic complications, such as cardiovascular events. RA affects about $0.5-1 \%$ of the general population worldwide and it involves any age group, with a predominance for the third, fourth and fifth decades [1]. RA is still considered an incurable disorder, even if disease remission

Tommaso Schioppo and Tania Ubiali contributed equally to this work.

Tommaso Schioppo

tommaso.schioppo@unimi.it

1 Division of Clinical Rheumatology, ASST Pini-CTO, Piazza Cardinal Ferrari 1, 20122 Milan, Italy

2 Department of Clinical Sciences and Community Health, Research Center for Adult and Pediatric Rheumatic Diseases, Research Center for Environmental Health, Università degli Studi di Milano, Milan, Italy

3 EPIGET LAB, Università degli Studi di Milano, Milan, Italy can be obtained with tight control and treat-to-target strategies, as suggested by current recommendations [2]. Disease flares occur in more than half of the patients and they substantially contribute to radiographic damage, poorer quality of life, disability, healthcare use, and costs [3, 4]. Presently, there are no predictors of therapy response and no indications about personalized treatment.

Despite recent advances, RA pathogenesis has not been completely elucidated yet. The genetic background plays a relevant role in RA susceptibility, but its contribution to the pathogenesis is partial [5]. Besides this, environmental factors, such as cigarette smoke and air pollution, have been identified as potential triggers for RA [6-8].

Extracellular vesicles (EVs) are membrane-contained vesicles released by cells in all biological fluids and they have been described as impaired in many pathological conditions, such as RA. EVs can transmit molecular effectors to other cells, thereby affecting the recipient cell function. EVs can be classified into three main groups: microvesicles, formed by external budding and fission of the plasma membrane; exosomes, produced within the cell and set loose after fusion of vesicular bodies with the plasma membrane; apoptotic bodies, released like blebs of apoptotic cells [9]. Studies on EVs 
made use of different terminology to describe EVs and this could pose difficulties for a direct comparison between them. For this reason, in our review, according to the last version of the position statement of the International Society for Extracellular Vesicles [10], we use the term EVs as a generic term to include the whole group of EVs.

Plasmatic EVs have been proposed as potential biomarkers. Furthermore, it has been suggested that EVs, after internalization into target cells through surface-expressed ligands, may transfer miRNAs, enabling inter-cellular and inter-organ communication [11]. To our knowledge, although several reviews have been published so far, none included a full systematic revision of the literature about EVs in RA [12-15].

It was against this background that we sought to explore the role of EVs in RA to present a complete and comprehensive recap about the state of the art on this topic.

\section{Materials and methods}

\section{Protocol and registration}

This review was conducted according to the Preferred Reporting Items for Systematic Reviews and Meta-Analyses (PRISMA) guidelines for reporting systematic reviews and meta-analyses $[16,17]$. Our protocol was registered on PROSPERO (CRD42020181164) [18].

\section{Literature search}

A comprehensive systematic literature search was undertaken using PubMed, Embase, and Scopus. The search strategy was planned to capture all the studies focusing on EVs in patients with RA with no restrictions for sex or therapies. The search terms were adapted according to bibliographic databases in combination with databasespecific filters, where these were available. The full search strategy is detailed in supplementary materials (table S1).

\section{Eligibility criteria}

Inclusion criteria: studies including adult patients with RA and investigating EVs, regardless of the technique applied. Clinical trials, observational studies (cross-sectional, prospective, and retrospective), case series (if subjects were $\geq 5$ ), studies with at least an abstract in English, and studies published from database inception to March 2020 were included.

Exclusion criteria: studies on patients under 18 years of age, review articles, animal or cell models, case reports or case series with $\leq 5$ subjects, and editorials were excluded.

\section{Data extraction and synthesis}

The research was performed on 5 March 2020. The citations were imported into the reference management software package Endnote X8. Duplicated references were automatically eliminated both by the Endnote software and manually by two reviewers (T.U. and T.S.).

During the first screening, the two reviewers independently screened titles/abstracts from the list of records retrieved, and full papers were sought when abstracts were felt to be relevant. Moreover, reference lists of the reviewed articles were examined for relevant studies. In cases of disagreement, a decision was made by consensus.

The two investigators, then, independently analyzed the full-text papers and extracted the relevant data from the included studies in standardized data extraction forms. The two authors then crosschecked the extracted data to rule out any discrepancies. Unresolved disagreements between two reviewers were resolved by consensus. The following data were evaluated: first author's surname, publication year, country, study design, setting, diagnostic criteria, outcomes measured, patient enrolment strategies, methods for EVs analysis, participant characteristics (age, gender, therapies), and results.

\section{Results}

\section{Literature review}

In total, 674 references were retrieved in the initial search strategy in Medline via PubMed, Embase, and Scopus. 333 references were excluded as duplicates. 268 references were excluded after title/abstract screening. Exclusion reasons were: studies not considering EVs $(n=61)$, basic science studies $(n=40)$, studies not considering RA $(n=102)$, type of articles (editorial/letter/comment/book; $n=55$ ), case reports $(n=8)$, duplicated $(n=2) .73$ articles were retrieved for full paper review of which 41 references fulfilled the inclusion criteria. Thirty-two manuscripts were excluded (exclusion reasons are reported in Fig. 1). The review flow process is outlined in Fig. 1. All the findings of the studies included in the present systematic review are reported in Table 1 and supplementary materials (table S2).

Regarding the methods used for EV analysis, the vast majority of the studies used flow cytometry specifying the different cluster of domain (CD); more information about the methods can be found in supplementary materials (table S2).

\section{EV concentration}

Total plasmatic EV number was higher in RA than healthy controls (HC), as reported in 4 studies for a 


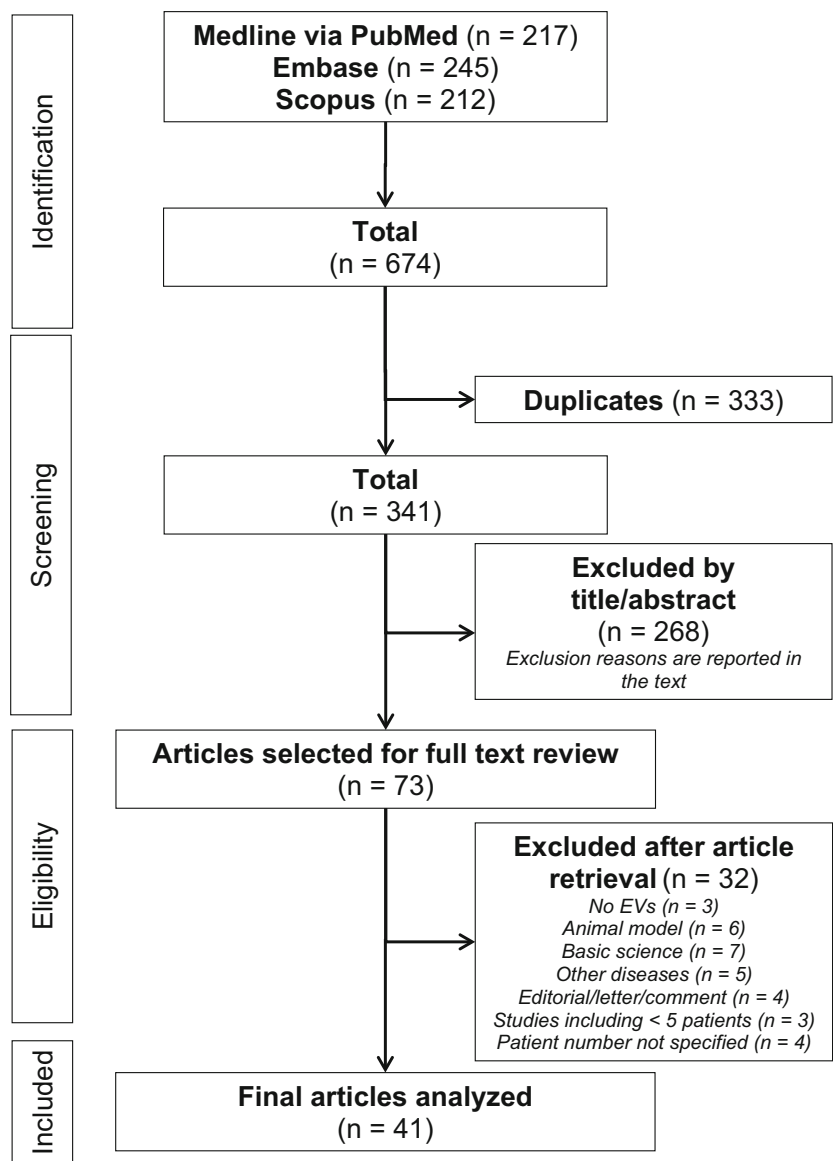

Fig. 1 PRISMA Flow diagram illustrating literature research and selection process

total of more than 180 patients $[19,23,51,54]$. However, in 3 studies for a total of 74 RA patients, the EV concentration was found similar between RA and HC [20, 24, 32]. Due to differences in techniques used for EV concentration, a metaanalysis could not be performed. Moreover, the EV number did not seem a specific biomarker as it was found similar in patients with reactive arthritis $(\operatorname{ReA})[21]$, undifferentiated arthritis (UA) [55], systemic lupus erythematosus (SLE) [54], primary Sjögren syndrome (pSS) [54], and osteoarthritis (OA) $[21,22]$.

According to one study on 41 RA patients, total plasmatic EV concentration was not different between seronegative and seropositive RA [20]. Surprisingly, in one study on 60 RA patients, EV count was found statistically different between $\mathrm{HC}$ and only a subpopulation of RA seropositive patients (not for those patients positive for rheumatoid factor- $\mathrm{RF}$, and anti-citrullinated peptides antibodies-ACPA, at high titer) [26].

Total EVs were higher in RA synovial fluid (SF) than HC plasma [24], OA SF [42, 51], and ReA SF [42]. RA SF EVs were at the same level when compared with RA plasma [24]. According to a different study, total EVs were higher in RA SF than in RA plasma [46].

\section{EV size}

EVs from RA patients were heterogeneous in size, mostly 100-300 $\mathrm{nm}$ and 700-3000 $\mathrm{nm}$ [33]. According to a different study, smaller EVs $(100 \pm 50 \mathrm{~nm})$ mostly derived from platelets (CD42+), while larger EVs (100-1000 nm) were more of $\mathrm{B}(\mathrm{CD} 19+)$ and T cells (CD3+) origin [36].

Plasmatic EV size was not different in RA as compared with HC $[20,38]$. Moreover, plasmatic EV size was found similar between seronegative and seropositive RA [20]. Another study found that RA seropositive for RF and ACPA (but not if seropositivity was at high titer) had a decreased proportion of $0.1-1 \mu \mathrm{m}$ and an elevated proportion of $1-3$ $\mu \mathrm{m}$ and 3-6 $\mu \mathrm{m}$ EVs, when compared with HC [26]. Moreover, EVs from seropositive individuals had higher frequencies and wider distribution of IgM+ and IgG+ EVs [26].

Of note, some of the aforementioned studies on EV dimensions could arise concerns about the methodology used (e.g., aggregation of EVs could not have been considered). Moreover, methods reporting EVs size are often not compliant with the latest recommendations [10] and this makes comparison across different studies insidious.

\section{EV cell origin}

Many of the studies included in this systematic review focused on surface molecules with the intent of unraveling EV origin and function. Therefore, various aspects were studied: platelets (CD41, CD42a, CD62P), leukocytes (CD45), T and B lymphocytes (CD3, CD4, CD8, CD20, CD154), granulocytes and monocytes (CD14, CD16, CD66b), endothelial cells (CD146, CD62P), and cell adhesion markers (CD31, CD61).

CD3+/HLA-DR+ [48], CD3+/CD4+ [48], CD146+ [19], $\mathrm{CD} 66 \mathrm{~b}+[19], \mathrm{CD} 31+[19,23], \mathrm{CD} 41+[37], \mathrm{CD} 42 \mathrm{a}$ [41], CD61+ [34, 41, 51, 54], and CD45+ [29] plasmatic EVs were found increased in RA when compared with HC. CD41+ [23], CD45+ [23, 54], CD66b+ [41], CD62P+ [49], CD154 [49], and CD16+ [41] plasmatic EVs were found similar between RA and HC. Of note, in a study on 55 RA patients, CD14+, CD41+, CD62E+, and CD20+ EVs were higher only in patients with high disease activity as compared with HC [57].

On the contrary, according to a different study, CD20+, CD4+, CD8+, CD14+, CD66b+ plasmatic EVs were not detectable in RA, as well as in OA patients [29]. CD45+ and CD61+ EVs were found at higher levels in RA than OA [29], whereas no difference was found for CD3+/HLA-DR+, $\mathrm{CD} 3+/ \mathrm{CD} 4+, \mathrm{CD} 3+/ \mathrm{CD} 8+\mathrm{EVs}$ between RA and OA [48]. Moreover, RA patients showed lower levels of CD45+ EVs than pSS [54] and of CD3+/CD8+ plasmatic EVs, when compared with EBV infection [48].

In RA SF, CD4+ [55], CD41+ [25], CD66+ [28, 55] and CD14+ $[28,55]$ EVs were found abundant, whereas glycophorin A [28, 55], CD4+ [28], CD61+ [28, 55], CD8+ 
Table 1 Characteristics of the included studies

\begin{tabular}{|c|c|c|c|}
\hline References & $\begin{array}{l}\text { Diagnosis and } \\
\text { patient number }\end{array}$ & RA therapies & Findings \\
\hline $\begin{array}{l}\text { Rodríguez-Carrio } \\
\text { J. (2015) [19] }\end{array}$ & $\begin{array}{l}114 \mathrm{RA}^{* *} \\
33 \mathrm{HC} \\
72 \mathrm{CV} \text { risk }\end{array}$ & $\begin{array}{l}\text { None or NSAIDs: } \\
\text { 10.5\%; GC: } 53.5 \% \text {; } \\
\text { MTX: } 70.1 \% \text {; TNFi: }\end{array}$ & $\begin{array}{l}\text { Total MPs: RA } 4.21 \text { vs. HC } 2.1(p<0.0001) \text { vs. CV risk } 3.14 \times 10^{6} / \mathrm{ml}(p=0.001) \\
\text { CD146+, CD66+, CD3CD31+ MPs were increased in RA vs. HC }(p=0.029, p= \\
0.001, p<0.001)\end{array}$ \\
\hline
\end{tabular}

39.4\%; TCZ: $10.5 \%$ RA total MPs were associated with traditional CV risk factors and with the number of $\mathrm{CV}$ risk factors

CD146+ was associated with disease duration $(p=0.005)$; CD66b+ with DAS28 ( $p=$ $0.032), \operatorname{ESR}(p=0.022)$, age at diagnosis $(p=0.021) ; \mathrm{CD} 3+\mathrm{CD} 31+$ with DAS28 ( $p$ $=0.007), \operatorname{TJC}(p=0.026), \operatorname{SJC}(p=0.003) ; \operatorname{CD} 14+$ with RF $(p=0.041)$

Patients in TCZ: lower CD3+CD31+ and CD66b+ $(p=0.005 ; p=0.011)$

Patients in MTX: lower CD3+DC31+ $(p=0.033)$

$\mathrm{TNF} \alpha$ correlated with $\mathrm{CD} 3+\mathrm{CD} 31+(p=0.097)$ if no traditional CV risk factors $(p<$ $0.0001)$. At multivariate regression model including $\mathrm{CV}$ risk factors, TNF $\alpha$ was associated with $\mathrm{CD} 3+\mathrm{CD} 31+(p=0.012)$

MPs from RA had a dose-dependant anti-angiogenic effect (CD14+ and CD41+ MPs) and endothelial activation (CD62E, CD144, VEGFR)

$\begin{array}{ll}\text { Arntz O.J. (2018) } & 41 \mathrm{RA}^{* *} \\ {[20]} & 24 \mathrm{HC}\end{array}$

Skriner K. (2006) 5 RA*

5 ReA

$5 \mathrm{OA}$

Atehortùa L. $\quad 9$ RA**

(2019) [22] 9 SLE

$6 \mathrm{HC}$
Barbati C. (2018) $20(+10) \mathrm{RA}^{* *}$ [23] $20 \mathrm{HC}$
DMARDs: 75\%; GC: 53.7\%; bDMARDs: $19.5 \%$

No difference in size, protein content concentration, concentration plasmatic EVs in RA vs. HC

No difference in size, content, concentration plasmatic EVs in RF+ vs. RF- (no difference between disease parameters apart from ESR higher in $\mathrm{RF}+, p<0.05$ )

In RF+: $13 / 28$ were found to have IgM-RF in EVs. Patients with IgM-RF on EVs had higher VAS, CRP, DAS28 and ESR $(p<0.001, p<0.01, p<0.05, p<0.01)$, no difference for TJC and SJC

Similar amount of exosomes in all patients

Citrullinated and non-citrullinated proteins present in all samples

Fibronectin/IgG immune complex only in RA exosomes

Endothelial cells internalized MPs and MPs-IC

Macrovascular HUVEC + MPs/MPs-IC $\rightarrow$ increase ICAM-1, ICAM-2, IL-6 and IL-8 (dose dependant for ICAM-1, IL-6 and IL-8)

Microvascular HMVEC-L + MPs-IC $\rightarrow$ increase in ICAM-1

Microvascular HMVEC-L + MPs $\rightarrow$ increase in CCL2

Microvascular HMVEC-L + MPs/MPs-IC $\rightarrow$ increase in CCL5

No effect of MPs/MPs-IC on HMVEC-D

HUVEC + MPs/MPs-IC $\rightarrow$ increase of adhesion of classical monocytes

HUVEC + MPs $\rightarrow$ increase of adhesion of non-classical monocytes (not for MPs-IC)

HMVEC-L + MPs/MPs-IC $\rightarrow$ decrease of adhesion of classical monocytes

MPs and more MPs-IC altered endothelial monolayers (micro- and macrovasculature) with increased permeability of macrovascular endothelial cells

ETN $50 \mathrm{mg}$ SC weekly Total MPs and endothelial MPs higher at baseline in RA vs. HC $(p<0.0001)$ (no + csDMARDS: 20; csDMARDs: 10

difference for platelet and leucocyte MPs)

After ETN: total MPs and endothelial MPs decreased from baseline $(p<0.0001$ and $p$ $=0.03$ )

At baseline TNF $\alpha$ was more expressed on MPs in RA than HC $(p=0.0009)$ with a decrease after 4 months of ETN ( $p=0.0002$ ) (no change for patients treated only with csDMARDs)

In vitro experiment: MPs-TNF $\alpha$ decreased dose-dependently after incubation with ETN

Significant correlation between MPs-TNF $\alpha$ and DAS28, TJC, SJC, CDAI, and HAQ

RA-MPs increased dose-dependently apoptosis and autophagy with respect to untreated cell $(p=0.005$ and $p=0.02)$

Complement activator products $(\mathrm{C} 4 \mathrm{~b} / \mathrm{c}$ and $\mathrm{C} 3 \mathrm{~b} / \mathrm{c})$ in RA SF were higher than RA plasma and $\mathrm{HC}(p<0.05, p<0.01, p<0.01, p<0.01)$; no difference between RA plasma and $\mathrm{HC}$

SAP and IgG in RA SF were lower than RA plasma and HC $(p<0.001, p<0.001, p<$ $0.01, p<0.01)$; no difference between RA plasma and $\mathrm{HC}$

CRP was higher in RA plasma than HC $(p<0.001)$; no difference between SF and plasma

IgM showed no difference between all groups

MPs were higher in RA SF than HC plasma $(p<0.05)$; no difference between RA plasma and HC or RA SF and RA plasma 
Table 1 (continued)

\begin{tabular}{llll}
\hline References & $\begin{array}{l}\text { Diagnosis and } \\
\text { patient number }\end{array}$ & RA therapies & Findings \\
\hline
\end{tabular}

MPs with C1q, C4, and C3 were higher in RA SF than RA plasma and HC plasma $(p<$ $0.01 ; p<0.05)$; no difference between RA plasma and HC plasma

MPs with CRP and SAP showed no difference between groups

MPs with IgM and IgG were higher in RA SF than RA and HC plasma $(p<0.05, p<$ $0.01, p<0.01, p<0.01)$

Boilard E. (2010) 20 RA

[25] $20 \mathrm{OA}$

6 JIA

19 PsA

14 Gout

Burbano C. (2018) [26]
$-$

anti-CCP $\mathrm{RF}^{-}=6$

anti-CCP ${ }^{+} \mathrm{RF}^{+/-}=$

26

anti-CCP ${ }^{\text {hi }} \mathrm{RF}^{\mathrm{hi}}=$

28

$40 \mathrm{HC}$
No bDMARDs

Platelet MPs are abundant in inflammatory SF (no statistical significance provided)

Plasma EV count: statistically different between $\mathrm{HC}$ anti- $\mathrm{CCP}^{+} \mathrm{RF}^{+/-}$(no difference for seronegative and anti-CCP $\mathrm{RF}^{\mathrm{hi}}$ )

EV size distribution: anti-CCP ${ }^{+} \mathrm{RF}^{+-}$and anti-CCP $\mathrm{RF}^{-}$had decreased proportions of $0.1-1 \mu \mathrm{m}$ and elevated proportions of 1-3 $\mu \mathrm{m}$ and 3-6 $\mu \mathrm{m}$ EV as compared with $\mathrm{HC}$

Cellular source: seropositives had more CD41a+ EVs and seronegatives had elevated CD105+ EVs

EV components: EV-ICs and EV-CPs were significantly elevated in seropositives as compared with $\mathrm{HC}$. Anti-CCP ${ }^{+} \mathrm{RF}^{+/-}$had higher C1q EVs and HMGB1 than other groups. EVs of seronegative patients were similar to HC. EV-ICs, EV-CPs, EV-C1q, and EV-HMGB1 derived from platelets and leukocytes (more from platelets in seropositives). EVs from seropostives had higher frequencies and wider distribution of EV-IgM+ and EV-IgG+ (on 5 patients for group)

EVs positive for IgG, IgM, CD41a, and citrulline were associated with systemic inflammation in seropositive patients

EVs from seropositive patients could activate mononuclear phagocytes and induce pro-inflammatory cytokines (TNF $\alpha$, IL-6, and IL-1beta)

$\begin{array}{cc}\begin{array}{c}\text { Burbano C. } \\ \text { (2019) [27] }\end{array} & \text { 34 } \mathrm{RA}^{* *} \\ & \text { (according to } \\ & \text { DAS28: 28 in } \\ & \text { remission and } \\ & 18 \text { in moderate } \\ & \text { activity) } \\ & \text { 34 SLE } \\ & \text { 14 HC } \\ \text { Berckmans R.J. } & \text { 10 RA* } \\ \text { (2002) [28] } & \text { 10 non-RA arthri- } \\ & \text { tis } \\ & 20 \mathrm{HC}\end{array}$

Michael B.N.R. 40 RA**

(2019) [29] 33 seropositive

7 seronegative

35 young-onset

15 extra-articular

manifestations

$30 \mathrm{OA}$

$33 \mathrm{HC}$
No bDMARDs

MP-ICs promote MDM differentiation to a pro-inflammatory profile (M1-like) more evident in SLE and RA than HC. MDM differentiated with MP-ICs from RA patients were resistant to repolarization to M2-like after IL4- treatment. MDM differentiated with MP-ICs from RA patients enhanced $\mathrm{T}$ cell proliferation, $\mathrm{B}$ cell activation markers, and $\mathrm{B}$ cell death prevention (not found for IFN $\gamma, \mathrm{TNF} \alpha$, and other B cells parameters)

RA: number of

DMARDs $2.6(0-5)$; non-RA: number of DMARDs $1.5(1-3)$

No therapy, GC included
MPs from RA plasma, but not from SF, strongly bound annexin V

Similar results for non-RA

MPs from platelets were absent in SF but were the most abundant in plasma $(p<$ $0.0001)$. The opposite was for granulocytes and monocytes $(p=0.0001, p<$ 0.0001). In SF, MPs from CD4+, CD8+, B cells and erythrocytes were low ( $p=$ $0.0001, p=0.0002,0=0.041, p=0.0001)$. No difference for RA and non-RA.

Thrombin-generating capacity (factor VIIa) for SF MPs was higher than patients' and HC plasma

TF was absent on SF MPs despite they initiated TF-mediated thrombin generation

Patients' plasma vs $\mathrm{HC}$ : prothrombin fragment $\mathrm{F}_{1+2}$ and thrombin-antithrombin were increased $(p<0.0001, p=0.0003)$. No difference for RA and non-RA SF $(p=0.16$ and 0.26). Higher levels in SF as compared with patients' plasma $(p<0.0001, p<$ $0.0001)$. Higher levels in RA plasma than non-RA plasma $(p=0.004, p=0.0003)$

SF from RA vs. OA: more annexin V, leucocyte-derived, monocyte-derived, granulocyte-derived MPs CD4+ and CD8+ MPs $(p<0.001, p<0.001, p<0.001, p$ $<0.001)$, B cell-derived not detectable in both

Granulocyte-derived MPs were more elevated in established RA SF than early RA ( $p$ $=0.03)$, annexin V MPs and platelet-derived MPs were increased in RA SF with extra-articular manifestations $(p=0.02, p<0.011)$, ACPA positive RA patients had more SF granulocyte MPs than ACPA negative $(p=0.02)$. There was a weak correlation between ACPA titer, CD4 MPs and granulocyte-derived MPs

Plasma annexin V and leucocyte-derived MPs were different in RA, OA and HC $(p<$ $0.001, p<0.001)$. RA plasma had more annexin $\mathrm{V}$, leucocyte-derived, platelet-derived MPs, and CD61 as compared with OA and $\mathrm{HC}(p<0.01, p<0.001$, $p<0.01, p<0.001, p<0.001, p=0.02, p<0.001)$. OA plasma had more annexin 
Table 1 (continued)

\begin{tabular}{llll}
\hline References & $\begin{array}{l}\text { Diagnosis and } \\
\text { patient number }\end{array}$ & RA therapies & Findings \\
\hline
\end{tabular}

$\mathrm{V}$, CD61 MPs vs. HC ( $p=0.002, p=0.01)$. Leucocyte-derived MP sub-populations (CD20, CD4, CD8, CD14, CD66b) were not detectable in plasma

No difference emerged for plasma MP profile among clinical and serological RA phenotypes

$\begin{array}{ll}\text { Chen Z. (2018) } & 11 \mathrm{RA}^{* *} \\ {[30]} & 11 \mathrm{OA}\end{array}$

$\begin{array}{ll}\text { Wang L. (2018) } & 25 \mathrm{RA}^{* *} \quad \text { No therapy } \\ 25 \mathrm{HC} & \end{array}$

Van Eijk I.C.

(2009) [32]

re-evaluated af-

ter 8 weeks)

$15 \mathrm{HC}$

Cloutier N. (2012) 23 RA

[33] 18 PsA

\begin{tabular}{|c|c|}
\hline $\begin{array}{l}\text { Knijff-Dutmer } \\
\text { E.A.J. (2002) } \\
\text { [34] }\end{array}$ & $\begin{array}{l}19 \text { RA* }^{*} \\
9 \text { active } \\
10 \text { inactiv } \\
10 \mathrm{HC}\end{array}$ \\
\hline $\begin{array}{l}\text { Xu D. (2018) } \\
\text { [35] }\end{array}$ & $\begin{array}{l}76 \mathrm{RA} \\
20 \mathrm{HC}\end{array}$ \\
\hline $\begin{array}{l}\text { Marton N. (2017) } \\
{[36]}\end{array}$ & $\begin{array}{l}20 \mathrm{RA}^{* *} \\
15 \mathrm{PsA} \\
19 \mathrm{HC}\end{array}$ \\
\hline $\begin{array}{l}\text { Gitz E. (2014) } \\
\text { [37] }\end{array}$ & $\begin{array}{l}10 \mathrm{RA}^{*} \\
10 \mathrm{HC}\end{array}$ \\
\hline $\begin{array}{l}\text { Greisen S.R. } \\
\text { (2017) [38] }\end{array}$ & $\begin{array}{l}5 \mathrm{RA}^{*} \\
5 \mathrm{HC}\end{array}$ \\
\hline
\end{tabular}

No therapy at baseline

(NSAIDs admitted)

Treated for 8 weeks with SSZ, MTX and GC: 9

MMP14 and VEGF expression were higher in RA than OA in serum $(p<0.001)$ and synovial tissue $(p<0.001)$

MMP14 and VEGF were higher in RA than OA in FLS $(p<0.001)$

miR-150-5p expression was lower in RA than OA in serum, synovial tissue, and FLS $(p<0.001)$

Exo150 downregulated MMP14 and VEGF expression in RA FLS and inhibited migration and angiogenesis in vitro $(p<0.001)$

Treg frequency was decreased in RA vs. HC and inhibited by RA-exosomes

RA exosomes resulted in a decreased Treg ratio vs. HC exosomes

miR-17, miR-19b, and miR-121 were overexpressed in RA

miR-17 had a negative correlation with Treg

miR-17 inhibited expression of TGFBRII and Treg induction

Total MPs were similar in RA and HC

MPs exposing C1q, CRP, and SAP were higher in RA vs. HC $(p<0.001)$

At baseline, ESR and CRP correlated with MPs exposing C1q, CRP, and SAP ( $p=$ $0.02 ; p<0.001 ; p=0.003 ; p=0.02 ; p=0.001 ; p=0.02$ )

After treatment, ESR, DAS28, and CRP decreased, whereas total circulating MPs and MPs exposing complement components or activator molecules were unaffected

MPs in RA were heterogeneous in size (mostly 100-300 and 700-3000 nm)

Annexin V MPs in RA were higher than PsA $(p=0.0004)$

In RA there were more MP-ICs and CD41+ MP-ICs than PsA $(p<0.0001 ; p=$ 0.0006)

Blockade of CD32a did not impede mpIC formation

Platelet MPs contained citrullinated epitopes and were recognized by ACPA (vimentin and fibrinogen)

MPs and MP-ICs stimulated leukotriene production by neutrophils

Platelet count was normal in all 3 groups

No anticoagulants and/or GC allowed; MTX: 6; SSZ: 5; gold: 2; HCQ: 4; LFN: 1 ; NSAIDs

PMPs were higher in RA than in HC $(p=0.05)$, with no difference between active and inactive disease

PMPs correlated with DAS28 in active RA patients $(p=0.05)$, but not with CRP or ESR

20 miRNAs were aberrantly expressed in serum exosomes from 3 RA (2 statistically significant: miR-548a-3p and miR-6891-3p)

miR-6089 was decreased in serum of RA vs. HC $(p<0.001)$

miR-6089 was reduced in PBMCs in RA vs. HC $(p<0.001)$

miR-6089 was negatively correlated with CRP, RF, and ESR $(p<0.001)$

DMARDs: $96 \%$; bDMARDs: $35 \%$

MVs from RA and PsA could not impair osteoclastogenesis

Presence of exosomes inhibited the ability of CD14+ monocytes to differentiate into TRAP+ multinucleated cells in RA and HC $(p<0.01)$, PsA-derived exosomes enhanced osteoclastogenesis $(p<0.05)$

RA and HC derived exosomes expressed higher levels of RANK than PsA $(p<0.05)$

In RA, exosomes were mostly platelet-derived (CD42b+), while MVs were more B cell (CD19+) and T cells (CD3+)

CD41+ MPs were higher in RA than HC $(p<0.01)$. CLEC-2 on CD41+ was similar. GPVI on CD41+ was lower in RA than HC $(p<0.01, p<0.01)$. Soluble GPVI was higher in RA than $\mathrm{HC}(p<0.01)$

Treatment according to EVs were present in plasma and SF RA: they could be isolated from PBMC and ACR $2015 \quad$ SFMC. EV size distribution did not differ between RA and HC cell cultures. PD-1 guidelines

is present in RA patients both in soluble form and in association with EVs

RA vs. HC PBMC: 12 miRNA, linked to PD-1/PD-ligands, were found different $(p<$ $0.05)$

miRNA content in EVs from RA SFMC, RA, and HC PBMC was different: a minor number of PD-1, PD-L1, and PD-L2 related miRNA changed in EVs generated from stimulation of RA SFMC 
Table 1 (continued)

\begin{tabular}{lll}
\hline References & $\begin{array}{l}\text { Diagnosis and } \\
\text { patient number }\end{array}$ & RA therapies
\end{tabular}

Gyorgy B. (2012) Plasma:

[39] $12 \mathrm{RA}^{* *}$

9 OA

SF:

$8 \mathrm{RA}^{* *}$

$8 \mathrm{OA}$

10 oligoarticular

JIA

$\begin{array}{ll}\text { Fan W. (2017) } & 34 \mathrm{RA}^{* *} \\ {[40]} & 33 \mathrm{OA} \\ & 42 \mathrm{HC}\end{array}$

Umekita K (2009) [41]

$$
\begin{aligned}
& 20 \mathrm{RA} *(6 \\
& \text { received } \\
& \text { LCAP) } \\
& 10 \mathrm{HC}
\end{aligned}
$$

$\begin{array}{clr}\text { Messer L. (2009) } & 7 \text { RA* } & \text { PDN: 100\%; MTX: } \\ \text { [42] } & 5 \text { OA } & \text { 100\%; IFX: 14\% } \\ & \begin{array}{c}3 \text { microcrystalline } \\ \text { arthritis }\end{array} & \\ & 5 \text { ReA } & \\ & & \\ \text { Jüngel A. (2007) } & 9 \text { RA* } & - \\ \text { [43] } & 7 \text { OA } & \end{array}$

8; SSZ: 5;

bucillamine: 4 ;
Data suggested that EVs transfer the co-inhibitory receptor PD-1 to cells in the microenvironment

Lymphocytes co-cultured with EVs had an increased PD-1 expression $(p<0.05)$

The number of lymphocytes co-cultured with EVs from RA PBMCs was higher than those co-cultured with HC PBMCs $(p<0.05)$

Data on 3 patients per group. In SF pellets, there were other particles besides MVs (proteins, immunecomplexes). Besides canonical MV proteins, many plasma proteins (albumin, transferrin, fibrinogen, prothrombin, haptoglobin) and immunocomplex related proteins (complement, immunoglobins) were present. No difference in the 3 groups.

Data on 8 patients for RA group. Annexin A MVs were not signifincatly elevated in RA vs. OA. Most MVs derived from B and T cells in RA e OA SF, lower monocyte and platelet MVs were present. CD3+ MVs were higher in RA than OA SF ( $p=$ $0.027)$. CD8+ MVs were higher in RA than OA SF $(p=0.009)$. B cell-derived MVs were lower in JIA than OA and RA SF ( $p=0.009, p=0.004)$. CD3 and CD8 MVs were undetectable in RA and OA plasma $(p<0.001)$, indicating local production. RANK and RANK-L associated MVs were found in all 3 groups.

$\mathrm{T}$ and $\mathrm{B}$ cell-derived MVs correlated to RF $(p=0.002, p=0.001)$. T and B cell-derived MV count correlated $(p<0.001)$. CD41 EVs correlated with disease duration $(p=0.008)$. SF cell number showed weak association with CD3 and CD8 MV counts $(p=0.039, p=0.017)$

CD4 MPs were higher in RA than OA and HC $(p<0.0052, p<0.0007)$. In CD4 MPs: CD161/CD39 MPs were higher in RA than OA and HC $(p<0.0045, p<0.0013)$, CD73/CD39 MPs were higher in RA than OA and HC $(p<0.0312, p<0.0065)$

CD161/CD39 MPs were positively correlated with DAS28, SJC and RF ( $p=0.007, p$ $=0.003, p=0.011)$. CD73/CD39 MPs were negatively correlated with DAS28, $\mathrm{SJC}$, and $\mathrm{RF}(p=0.004, p=0.018, p=0.014)$

In RA FLSs culture, CD161/CD39 MPs increased CCL2 0 production $(p<0.002)$, CD73/CD39 MPs increased CCL17 and CCL22 production $(p<0.0018, p<$ 0.0022). No effects for HC MPs

In RA PBMCs culture CD161/CD39 MPs increased IL-17 production $(p<0.0045)$, CD39/CD73 MPs inhibited IL-17 production and increased IL-10 production $(p<$ $0.0217, p<0.0156)$. No effects for HC MPs

PDN: 12 (mean dosage Mean CD61 and CD42a were higher in RA than $\mathrm{HC}(p<0.0001, p<0.0001)$. No $6.4 \mathrm{mg} / \mathrm{die})$; MTX: difference for CD66b and CD16 MPs in RA and HC

CD61 MPs correlated with CRP, ESR, DAS28 $(p=0.02, p=0.002, p=0.0126)$. CD42a correlated with ESR $(p=0.01)$

tacrolimus: 3; LFN: After the first section of LCAP: CD61 and CD42a MPs decreased $(p<0.05)$, CD66b and CD16 MPs increased $(p<0.01)$

After 8 weeks of follow-up (5 LCAP): DAS28 and DAS28-CRP decreased significantly, mean numbers of CD61 and CD42a MPs decreased $(p=0.004, p=$ 0.005), mean numbers of CD66b and CD16 MPs did not change.

MPs from SF were higher in RA and microcrystalline arthritis than OA and ReA ( $p<$ $0.05, p<0.05$ )

The ability of RA FLS to induce BAFF, IL-6, and IL-8 after stimulation of MPs is independent from MP origin (OA or RA)

RA FLS released TSLP protein and SLPI after MPs exposure (not only derived from RA SF)

RA and OA synovial fibroblasts, incubated with MPs, produced PGE2 dose-dependently $(p<0.005)$. PGE $_{2}$ was not present in MPs. No difference according to MPs origin

Incubation of RA and OA synovial fibroblasts with MPs did not increase phospholipase A2 release. MPs dose-dependently induced COX-2 and mPGES-1 mRNA in RA and OA synovial fibroblasts $(p<0.05, p<0.05)$, not COX-1, mPGES-2, and cytosolic PGES. No difference according to MPs origin

Upregulation of $\mathrm{PGE}_{2}$ was mainly mediated via COX-2 $(p<0.05)$

MPs activated NF-kB and AP-1 signaling in synovial fibroblasts. There was a significant reduction of the induction of mPGES-1 by MPs in RA synovial fibroblasts, when NF-kB and AP-1 were inhibited $(p<0.05, p<0.05)$ 
Table 1 (continued)

\begin{tabular}{lll}
\hline References & $\begin{array}{l}\text { Diagnosis and } \\
\text { patient number }\end{array}$ & RA therapies
\end{tabular}

\begin{tabular}{|c|c|c|c|}
\hline & & & $\begin{array}{l}\text { MPs increased } \mathrm{p} 38 \text { and } \mathrm{JNK} \text {, but only the inhibition of } \mathrm{JNK} \text { caused a significant } \\
\text { reduction in } \mathrm{PGE}_{2} \text { production } \\
\text { MPs transferred arachidonic acid into sinovial fibroblasts }\end{array}$ \\
\hline $\begin{array}{l}\text { Wang Y. (2017) } \\
\text { [44] }\end{array}$ & $\begin{array}{l}76 \mathrm{RA} \\
20 \mathrm{HC}\end{array}$ & - & $\begin{array}{l}\text { RA miR-548-3p was downregulated in serum and PBMCs exosomes vs. HC ( } p< \\
0.001) \\
\text { Low levels of miR-548a-3p were associated with higher levels of CRP, RF, and ESR } \\
(p<0.001) \\
\text { miR-548a-3p was involved in TLRs-mediated response (in particular TLR4 and } \\
\text { NF-kB) }\end{array}$ \\
\hline $\begin{array}{l}\text { Szabó-Taylor } \\
\text { K.É. (2017) } \\
\text { [45] }\end{array}$ & $\begin{array}{l}71 \mathrm{RA}^{* *} \\
54 \mathrm{HC}\end{array}$ & - & $\begin{array}{l}\text { Exofacial thiol EV levels decreased upon LPS stimulation of U397 cells }(p<0.05) \text {. } \\
\text { Monocytes from RA }(n=6) \text { released EVs with lower exofacial thiol content vs. HC } \\
(p<0.001) \\
\text { Plasma-derived EV esofacial thiols did not show any difference between RA and HC } \\
(\text { CD9, CD41a, annexin V), while total plasma thiol levels were lower in RA vs. HC } \\
(p<0.0001) \\
\text { Higher number of plasma exofacial peroxiredoxin-1 positive EVs in RA }(n=16) \text { vs. } \\
\text { HC }(p<0.05)\end{array}$ \\
\hline $\begin{array}{l}\text { Headland S.E. } \\
\text { (2015) [46] }\end{array}$ & $\begin{array}{l}7 \text { RA (blood+SF) } \\
22 \text { RA (SF) } \\
\text { HC }\end{array}$ & $\begin{array}{l}\text { No treatment: } 2 \text {; GC: } 3 \text {; } \\
\text { DMARDs: } 3 \text {; } \\
\text { bDMARDs: } 3 \\
\text { No treatment: } 0 \text {; GC: } 3 \text {; } \\
\text { DMARDs: } 13 \text {; } \\
\text { bDMARDs: } 0\end{array}$ & $\begin{array}{l}\text { There were more total, CD66b, CD14, and CD3 MVs in SF than in plasma }(p=0.005 \text {, } \\
p=0.016, p=0.022, p=0.008) \text {. SF MVs had more annexin A1 than plasma MVs, } \\
\text { with more annexin A1 MV of neutrophil origin. In SF, there were more neutrophil } \\
\text { MVs than monocyte or T cell MVs }(p<0.001, p=0.001) \text {, with more annexin A1 }(p \\
<0.001 \text { for both) }\end{array}$ \\
\hline $\begin{array}{l}\text { Chen X.M. } \\
\text { (2020) [47] }\end{array}$ & $\begin{array}{l}15 \text { RA** } \\
30 \text { PsA } \\
15 \text { psoriasis } \\
15 \text { gout } \\
15 \text { HC }\end{array}$ & $\begin{array}{l}\text { No therapy in the } \\
\text { previous } 4 \text { weeks }\end{array}$ & $\begin{array}{l}198 \text { and } 31 \text { microRNAs were up- and downregulated, respectively, in RA vs. HC } \\
36 \text { commonly expressed microRNAs were identified ( } 29 \text { up- and } 7 \text { downregulated) vs. } \\
\text { HC } \\
5 \text { microRNAs (hsa-miR-151a-3p, hsa-miR-199a-5p, hsa-miR-370-3p, } \\
\text { hsa-miR-589-5p, and hsa-miR-769-5p) were considered to be connected with the } \\
\text { common pathogenesis of PsA, psoriasis, RA, and gout }\end{array}$ \\
\hline $\begin{array}{l}\text { Oba R. (2019) } \\
\quad[48]\end{array}$ & $\begin{array}{l}20 \mathrm{RA} \\
20 \mathrm{OA} \\
13 \mathrm{EBV} \\
10 \text { atopic } \\
\quad \text { dermatitis } \\
20 \mathrm{HC}\end{array}$ & - & $\begin{array}{l}\text { CD3 and CD4 were included in both Th1 and Th2 derived EVs } \\
\text { Alpha and beta chains of HLA-DR were dominant in Th1 derived EV vs. Th2 derived } \\
\text { EVs } \\
\text { CD3+ HLA-DR+ EVs were higher in Th1 than Th2 (no diffeernce for CD3/CD4+ and } \\
\text { CD3/CD63+) } \\
\text { CD3+HLA-DR+ EVs were similar in RA and OA vs. HC } \\
\text { CD3+CD4+ EVs were higher in all four diseases vs. HC (RA vs. HC: } p<0.05 \text { ) } \\
\text { CD3+CD8+ EVs were higher in EBV infection and lower in RA }(p<0.01)\end{array}$ \\
\hline $\begin{array}{l}\text { Villar-Vesga J. } \\
\text { (2019) [49] }\end{array}$ & $\begin{array}{l}18 \mathrm{RA}^{* *} \\
\text { All positive for } \\
\text { ACPA and/or } \\
\text { RF } \\
41 \mathrm{HC}\end{array}$ & No biologics & $\begin{array}{l}\text { Platelets were a frequent source of MPs ( } 50 \% \text { in RA and } 40 \% \text { in } \mathrm{HC} \text { ) with platelet } \\
\text { activation markers (CD62P, CD154, annexin V, and DIOC6). RA had more } \\
\text { citrullinated peptides and IgG MPs than } \mathrm{HC}(p \leq 0.05 ; p \leq 0.01) \\
\text { Platelets from HC produced MPs when stimulated with collagen type IV, similarly to } \\
\text { RA }\end{array}$ \\
\hline $\begin{array}{l}\text { Reich N. (2011) } \\
\text { [50] }\end{array}$ & $\begin{array}{l}12 \text { RA }^{*} \\
9 \text { for RA synovial } \\
\text { fibroblasts } \\
3 \text { for SF }\end{array}$ & $\begin{array}{l}\text { MTX: 8; GC: 7; ADA: } \\
\text { 4; ETN: 1; RTX: 2; } \\
\text { LFN 1; IFX: } 1\end{array}$ & $\begin{array}{l}\text { Expression of chemokines in RA synovial fibroblasts co-incubated with MPs from } \\
\text { Jurkat T cells, U937 monocytes, and SF was increased (CXCL1, CXCL2, } \\
\text { CXCL3x, CXCL5, and CXCL6) } \\
\text { Supernatants from RA synovial fibroblasts co-incubated with MPs induced migration } \\
\text { of ECs in transwell chamber assays vs. supernatants without MPs ( } p=0.01 \text { ) and } \\
\text { neutralizing antibodies reduced the stimulatory effect } \\
\text { Supernatants did not affect proliferation or viability of ECs (number of apoptotic or } \\
\text { necrotic cells unchanged) }\end{array}$ \\
\hline $\begin{array}{l}\text { Michael B.N.R. } \\
\text { (2018) [51] }\end{array}$ & $\begin{array}{l}23 \mathrm{RA}^{* *} \\
17 \mathrm{OA} \\
22 \mathrm{HC}\end{array}$ & No DMARDs & $\begin{array}{l}\text { SF MPs were higher in RA than OA }(p<0.0001) \text {, SF PMPs were higher in RA than } \\
\text { OA }(p=0.0472) \text {, SF non-PMPs were also higher }(p<0.0001) \\
\text { Plasma MPs were higher in RA }(p<0.0001) \text { and OA }(p<0.01) \text { vs. HC, plasma PMPs } \\
\text { were higher in RA }(p<0.0001) \text { and OA }(p<0.01) \text { vs. HC, plasma non-PMPs were } \\
\text { higher in RA }(p<0.0001) \text { and OA }(p<0.01) \text { vs. HC }\end{array}$ \\
\hline $\begin{array}{l}\text { Liao T. L. (2018) } \\
\quad[52]\end{array}$ & $\begin{array}{l}40 \mathrm{RA}^{* *} \text { with } \\
\text { active disease }\end{array}$ & $\begin{array}{l}\text { csDMARDs, ADA, } \\
\text { ETN, GOL, RTX }\end{array}$ & $\begin{array}{l}\text { miR-155 was increased in PBMCs in RA patients with HCV vs. patients without HCV } \\
\quad(p<0.001) \text { and it suppressed HCV replication }(p<0.01)\end{array}$ \\
\hline
\end{tabular}

\footnotetext{
[52] active disease ETN, GOL, RTX
} 
Table 1 (continued)

\begin{tabular}{llll}
\hline References & $\begin{array}{l}\text { Diagnosis and } \\
\text { patient number }\end{array}$ & RA therapies & Findings \\
\hline
\end{tabular}

$(\mathrm{DAS} 28>3.2)$

after

csDMARDs

20 with cronic

$\mathrm{HCV}$

20 without $\mathrm{HCV}$

Rodríguez-Carrio $13 \mathrm{RA}$

J. (2015) [53] $33 \mathrm{HC}$

$\begin{array}{cl}\text { Sellam J. (2009) } & 24 \mathrm{RA}^{*} \\ & 43 \mathrm{pSS} \\ & 20 \mathrm{SLE} \\ & 44 \mathrm{HC}\end{array}$

Berckmans R. J. 8 RA*

(2005) [55] 3 UA

Tsuno H. (2018) 12 active RA*

[56]

(DAS28 > 2.7)

11 inactive RA*

(DAS28<2.3)

$10 \mathrm{OA}$

$10 \mathrm{HC}$

$\begin{array}{cl}\text { Viñuela-Berni V. } & 55 \mathrm{RA}^{*} \\ \text { (2015) [57] } & 6 \text { remission } \\ & 6 \mathrm{LDA} \\ & 22 \mathrm{MDA} \\ & 21 \mathrm{HDA} \\ & 14 \mathrm{SLE} \\ & 20 \mathrm{HC}\end{array}$

Yoo J. (2017) [58] $60 \mathrm{RA}^{* *}$
$30 \mathrm{CR}$

(DAS28ESR $\leq$

2.6)

30 non-CR

(DAS28 > 2.6)
RA patients with HCV had higher exo-miR-155 levels vs. HCV negative $(p<0.01)$, RA patients with HCV treated with RTX had decreased exo-miR-155 expression vs. TNFi or csDMARDs $(p<0.05)$

TNFi naive; GOL: 11 or ETN: for 3 months; all on MTX; GC: 10

Tang and EPC increased after treatment, Tang reached levels similar to $\mathrm{HC}(p=0.522)$ DAS28 decreased $(p<0.001)$ and paralleled Tang increased $(p=0.011)$

Tang increase was greater in good responders $(p=0.03)$, only good responders displayed parallel increase of Tang and EPCs $(p=0.037)$; treatment was associated with decreasing VEGF $(p=0.002)$, leptin $(p=0.014)$, SDF1a $(p=0.002)$ in the whole group, IL-8 and TNF $\alpha$ in good responders $(p=0.045)$

Tang-MP shedding was decreased after treatment $(p=0.021)$, especially in good responders $(p=0.006)$

GC less than $10 \mathrm{mg}$; MTX: 16; anti-TNF: 5; LFN: 2

Patients with pSS $(p<0.0001)$, SLE $(p=0.0004)$ and RA $(p=0.004)$ showed increased plasma levels of total MPs vs HC. No difference between pSS, RA and SLE

All showed increased levels of platelet MPs $(p<0.0001)$, pSS also increased leukocyte MPs $(<0.0001)$ and higher vs. RA $(p=0.015)$ and SLE $(p=0.003)$

Leukocytes MPs and DAS28 showed negative correlation in RA $(p=0.005)$

Total and platelet MPs were inversely correlated with sPLA2 activity in all groups ( $p=$ 0.0007 and $p=0.002$ )

DMARDs 4.5 in RA MPs numbers in UA and RA were similar

SF from RA and UA contained MPs of monocytic (CD14) and granulocytic (CD66e) origin and low levels of MPs from platelets and erythrocytes; MPs from B cells were present in 2 RA patients; MPs from CD8+ T cells

SF MPs + FLS: increase in MCP-1 $(p=0.01)$, sICAM-1 $(p=0.01)$, IL-8 $(p=0.008)$, IL-6 $(p=0.042)$, VEGF $(p=0.001)$, RANTES $(p=0.031)$, and decrease in GM-CSF $(p=0.002)$.

Total number and granulocyte-derived MPs of SF MPs and plasma MPs correlated with IL-8 $(p<0.0001)$ and MCP-1 $(p<0.0001)$; monocytes-derived MPs did not

204 protein spots were detected on the gel

In RA 28/204 protein spots had different intensity $(p<0.05)$, in particular 7 of these

In active RA 24 spots showed $\geq 1.3$-fold intensity differences vs. HC, in inactive RA 5 spots (only 2 overlapped with active RA)

Six protein spots were identified, among which TLR3 showed 6-fold higher intensity in active RA group vs. the others

The band intensity of TLR3 fragments (17-18 kDa) was higher in RA vs. HC $81.8 \%$; bDMARDs: $18.1 \%$

DMARDS (MTX, SSZ), PDN: 31 ; no treatment: 20

For the 8 patients prospectically followed: MTX, SSZ, and PDN

Levels of Annexin V+ MPs derived from monocytes (CD14+), platelets (CD41a+), $\mathrm{EC}(\mathrm{CD} 62 \mathrm{E}+)$ and B cells (CD19+) were enhanced in HDA RA vs. HC $(p<0.001)$; no difference for LDA and $\mathrm{HC}$

MDA RA had enhanced levels of CD14+ and CD62E+ MPs $(p<0.05)$

Differences in urine levels of CD14+ and CD19+ between LDA and HDA

Correlation between plasma and urine levels of MPs and DAS28 $(p<0.05)$

No difference in MPs levels between treated and untreated patients

Decrease in plasma levels of all MPs after 4 weeks of therapy $(p<0.05)$ and urine MPs levels of CD14+, CD41+ and CD3+ MPs $(p<0.05)$

Mononuclear cells from HDA stimulated with MPs induced release of IL-1, IL-17, and TNF $\alpha$, and an association between release of IL1 and TNF $\alpha$ and DAS28 was observed $(p<0.05)$

Six candidate proteins identified

Serum and exosomal AA protein levels were higher in non-CR vs. CR $(p=0.001)$, serum and exosomal AA levels correlated $(p=0.001)$

Serum CRP correlated with serum AA in CR $(p=0.001)$ and in non-CR $(p<0.001)$

Serum CRP correlated with exosomal AA in non-CR $(p<0.001)$, but not in CR

Exosomal levels of LYVE-1 were lower in non-CR vs. CR $(p=0.01)$, no difference between serum LYVE-1 levels in CR and non-CR; there was a weak correlation between serum and exosomal LYVE-1 
Table 1 (continued)

\begin{tabular}{lll}
\hline References & $\begin{array}{l}\text { Diagnosis and } \\
\text { patient number }\end{array}$ & RA therapies
\end{tabular}

$\begin{array}{ll}\text { Zhang H. G. } & 10 \mathrm{RA}^{*} \\ \text { (2006) [59] } & 10 \mathrm{OA}\end{array}$

There was a positive correlation between serum and exosomal LYVE-1 and CRP in non-CR $(p=0.04, p=0.002)$ and a negative correlation between anti-CCP titer and exosomal LYVE-1 in non-CR $(p=0.014)$

Membrane-bound TNF $\alpha$ detected on exosomes was produced by RA synovial fibroblasts but not OA synovial fibroblasts; exosomes expressed only the membrane-bound TNF $\alpha$ but not the soluble form

RA synovial fibroblasts exosomal TNF $\alpha$ induced cytotoxicity of L929 cells, not OA synovial fibroblasts; preincubation with a TNF antagonist blocked the effect

RA synovial fibroblasts exosomes induced activation of NFkB signaling pathway in RA synovial fibroblasts, not OA synovial fibroblasts exosomes, but RA synovial fibroblasts exosomes induced NFkB in OA synovial fibroblasts; the TNF antagonist neutralized the effect

RA synovial fibroblasts exosomes induced MMP-1 in RA synovial fibroblasts, less with TNFi $(p<0.0018)$, not OA synovial fibroblasts exosomes

TNF $\alpha$ stimulated production of RA synovial fibroblasts exosomes $(p<0.0011)$, slightly for OA synovial fibroblasts exosomes; TNFi reduced the effect

Coculture of RA synovial fibroblasts exosomes with CD4+T cells resulted in sustained cell proliferation and induction of IFN $\gamma$ and IL-2 (not OA synovial fibroblasts exosomes) and TNFi partially reversed the effect

In $\mathrm{T}$ cells, phosphorylated Akt was induced and NFkB activity increased

*1987 ACR criteria; **2010 EULAR/ACR criteria

$A A$ : amyloid A; $A C R$ : American college of rheumatology; ADA: adalimumab; Anti-CCP: anti-citrullinated protein antibodies; $A C P A$ : anti-citrullinated protein antibodies; $C D A I$ : clinical disease activity index; $C P$ : citrullinated peptides; $C R$ : clinical remission; $C R P$ : C-reactive protein; $C V$ : cardiovascular; $D A S 28$ : disease activity score on 28 joints; DMARDs: disease modifying anti-rheumatic drugs (b-: biological; cs-: conventional synthetic); $E B V$ : EpsteinBarr virus; $E C$ : endothelial cell; $E P C$ : endothelial progenitor cell; $E S R$ : erythrocyte sedimentation rate; $E T N$ : etanercept; $E V s$ : extracellular vesicles; FLS: fibroblast-like synoviocytes; GC: glucocorticoid; GOL: golimumab; $H A Q$ : health assessment questionnaire; $H C$ : healthy controls; $H C Q$ : hydroxychloroquine; $H C V$ : hepatitis $\mathrm{C}$ virus; $H D A$ : high disease activity; $H M G B 1$ : high mobility group box 1 ; $H M V E C$ : human microvascular endothelial cells (-D: dermal; -L: lung); HUVEC: human umbilical vein endothelial cells; IC: immunocomplexes; IFX: infliximab; JIA: juvenile idiopathic arthritis; $L C A P$ : leukocytapheresis; $L D A$ : low disease activity; $L F N$ : leflunomide; $M D A$ : moderate disease activity; $M D M$ : monocytederived macrophages; $M P s$ : microparticles; $M T X$ : methotrexate; $M V s$ : microvesicles; NSAIDs: non-steroidal anti-inflammatory drugs; OA: osteoarthritis; PBMC: peripheral blood mononuclear cells; PDN: prednisone; PMPs: platelet microparticles ; PLA2s: phospholipases A2; PsA: psoriatic arthritis; $p S S$ : primary Sjögren syndrome; $R A$ : rheumatoid arthritis; ReA: reactive arthritis; $R F$ : rheumatoid factor; $R T X$ : rituximab; SAP: serum amyloid protein; $S C$ : subcutaneous; SF: synovial fluid; SFMC: synovial fluid mononuclear cells; SJC: swollen joint count; SLE: systemic lupus erythematous; SLPI: secretory leucocyte protease inhibitor; SSZ: sulfasalazine; Tang: angiogenic T cells; TCZ: tocilizumab; TF: tissue factor; TJC: tender joint count; TNFi: tumor necrosis factor inhibitor; TSLP: thymic stroma lymphopoietin; VAS: visual analog scale; UA: undifferentiated arthritis

$[28,55]$, and CD20+ $[28,55]$ EVs were low. These differences were not specific for RA, since they were also found in non-RA arthritis SF [28].

RA SF contained more CD61+ [51], CD45+ [29], CD3+ [39], CD4+ [29, 40], CD4+/CD161+/CD39+ [40], CD4+/ CD73+/CD39+ [40], CD8+ [29, 39], CD14+ [29], and CD66+ [29] EVs than OA SF, whereas there was no difference for CD20+ EVs [29]. Annexin A1+, CD66b+, CD14+, and CD3+ EVs were higher in RA SF than RA plasma [46]. SF CD66b+ EVs were more abundant than CD14+ and CD3+ EVs [46], whereas CD3+ and CD8+ EVs were absent in plasma [39].

\section{EV content}

More citrullinated peptides and IgG were found in EVs, when compared with HC, in a study on 18 RA patients [49]. Citrullinated and not-citrullinated proteins were also present in RA, OA, and ReA, but fibronectin/IgG immunocomplexes
(ICs) were found only in RA EVs [21]. According to another study, platelet EVs contained citrullinated epitopes, which were recognized by ACPA (vimentin and fibrinogen) [33]. Plasmatic EV protein content was not different in seronegative and seropositive RA [20]. IgM-RF was found in EVs in about half of RA patients seropositive for RF [20]. Burbano C. et al. found differences according to seropositivity: IC-EVs were higher in seropositive patients, whereas there was no difference in seronegative patients, as compared with HC [26]. Moreover, a similar difference between seronegative and seropositive patients was observed concerning systemic inflammation and EVs positive for $\operatorname{IgG}, \operatorname{IgM}, \mathrm{CD} 41$, and citrulline [26]. Furthermore, there were more IC-EVs in RA patients than in psoriatic arthritis (PsA) [33]. EVs with IgM and IgG were higher in RA SF than RA and HC plasma [24].

EVs with C1q, C3, and C4 were higher in RA SF than HC and RA plasma, while no differences were found between RA and HC plasma [24]. On the contrary, plasmatic EVs with C1q 
were higher when compared with $\mathrm{HC}$ in a study on 24 RA patients [32].

EVs with C-reactive protein (CRP) and serum amyloid $\mathrm{P}$ (SAP) were not different between RA and HC [24], whereas EVs with CRP and SAP were higher, as compared with $\mathrm{HC}$ in another study [32]. Serum and EV amyloid A (AA) levels were higher in patients with active disease than in patients in clinical remission [58]. Moreover, serum and EVs AA levels correlated with each other [58].

We found 6 studies that reported results on EVs miRNA. miR-150-5p expression was lower in RA than OA [30]. miR6089, miR-6891-3p, and miR-548-3p were decreased in the serum of RA as compared with HC [35, 44]. miR-17, miR19b, and miR-121 were overexpressed in RA [31]. Moreover, miR-6089 was found to negatively correlate with CRP, RF, and ESR [35]. Fan W. et al. found that 36 miRNAs (see Table 1 for details) were differently regulated in RA compared with HC [47]. In this study, 5 miRNAs (hsa-miR-151a-3p, hsa-miR-199a-5p, hsa-miR-370-3p, hsa-miR-589-5p, and hsa-miR-769-5p) were present in different forms of inflammatory arthritis (PsA, RA and gout) [47]. Moreover, 12 miRNAs, linked to programmed death (PD)-1/PD-ligands, were identified [38].

Thrombin-generating capacity (factor VIIa) was higher for SF EVs than plasma from RA patients and HC. No tissue factor (TF) antigen was present on SF EVs despite they were able to initiate TF-mediated thrombin generation [28]. C-type lectin-like receptor 2 (CLEC-2) on CD41+ EVs were similar, whereas GPIV on CD41+ were higher in RA than HC [37].

In RA patients, plasmatic EVs were found strongly bound to annexin $\mathrm{V}$ [22] and at a higher concentration than $\mathrm{HC}$ [29] and PsA [33]. This was not confirmed by a different study, since Annexin V+ EVs did not differ between RA and HC [49]. RA SF EVs boundless annexin V as compared with plasmatic EVs [28] and their number was not significantly elevated, as compared with OA [39]. Moreover, RA SF contained more annexin $\mathrm{V}+$ [29] EVs than OA SF.

Furthermore, evidence from single studies suggested a potential role for PD-1 [38], TNF- $\alpha$ [59], RANK [36], TLR4 [44], and TLR3 [56].

\section{EV biological effect}

Many studies focused on EV effects on pathways related to inflammation. Plasmatic EVs and IC-EVs enhanced adhesion molecules (ICAM-1, ICAM-2), inflammatory cytokines (IL6, IL-8), and chemokines (CCL-2, CCL-5) from endothelial cells increasing vascular permeability [22] and leukotriene release from neutrophils [33].

Plasmatic EVs from seropositive patients [26] and plasmatic EVs from patients with high disease activity [57] stimulated mononuclear phagocytes to release pro-inflammatory cytokines: TNF $\alpha$ [26, 57], IL-6 [26], IL-17 [57], and IL-1 [26, 57].
RA fibroblast-like synoviocytes (FLS) induced a decrease in GM-CSF [55] and an increase in MCP-1 [55], sICAM-1 [55], VEGF [55], RANTES [55], BAFF [42], IL-6 [42, 55], and IL-8 $[42,55]$ after stimulation with SF EVs. In one of the two studies, this ability was independent from EV origin (OA or RA) [42].

EVs from Jurkat cells stimulated the induction of several chemokines (CXCL1, CXCL2, CXCL3X, CXCL5, and CXCL6) [50] in RA synovial fibroblasts. Moreover, EVs in RA synovial fibroblasts were demonstrated to play a role in MMP-1, IFN- $\gamma$, and IL-2 secretion [59]: as expected, these biological effects were partially reduced with the exposure of TNF inhibitors [59]. RA synovial fibroblasts EVs promoted NFkB signaling pathway in both RA and OA synovial fibroblasts [59]. RA synovial fibroblasts incubated with EVs from HC produced dose-dependently PGE2 regardless of EVs origin without increasing phospholipase A2 [43]. EVs dosedependently induced COX-2 and mPGES- 1 mRNA in RA synovial fibroblasts, but not COX-1, mPGES-2, and cytosolic PGES [43]. Moreover, EVs were also able to transfer arachidonic acid from leukocytes into synovial fibroblasts [43]. Levels of total and platelet plasmatic EVs were inversely correlated with secretory phospholipase A2 (sPLA2) activity in one study [54].

SF CD161+/CD39+ EVs increased CCL20 production, SF CD73+/CD39+ EVs increased CCL17 and CCL22 synthesis in RA fibroblasts, whereas SF CD161+/CD39+ EVs increased IL17 production, and SF CD39+/CD73+ EVs reduced IL-17 and increased IL-10 production in PBMC in RA [40].

EVs were also found involved in intracellular proinflammatory pathways, in particular NFkB. EVs from HC activated NF-kB and AP-1 signaling in RA synovial fibroblasts and they increased p 38 and JNK, but only the inhibition of JNK caused a significant reduction in PGE2 production [43].

RA IC-EVs promoted more macrophages differentiation towards a pro-inflammatory profile (M1-like) than HC [27]. Macrophages differentiated with RA IC-EVs were resistant to repolarization to M2-like after treatment with IL-4 [27]. Macrophages were also able to enhance $\mathrm{T}$ and $\mathrm{B}$ cells and prevent B cell death [27]. Plasmatic RA EVs inhibited Treg, possibly through miRNAs (miR-17) [31].

Plasmatic CD14+ and CD41+ EVs from RA patients showed an anti-angiogenic effect, while CD62E+ and CD144+ EVs promoted endothelial activation [19]. RA plasmatic EVs increased dose-dependently apoptosis and autophagy of endothelial cells [23]. In vitro evidence suggested that SF EVs were able to induce ECs migration without affecting ECs proliferation or viability [50]. Exo150 downregulated the expression of MMP14 and VEGF in RA FLS and inhibited migration and angiogenesis in vitro [30].

One study provided interesting but non-conclusive insights about the role of exofacial thiol EVs and oxidative stress resistance that could also play a role in RA [45]. 


\section{EVs and disease characteristics}

Plasmatic CD146+ EVs [19] and SF CD41+ EVs [39] levels correlated with disease duration. SF CD66b+ EVs were more abundant in established RA than early RA [29], and they were associated with the age at diagnosis [19].

A positive association was found between $\mathrm{RF}$ and plasmatic CD14+ [19], SF CD3+ [39], SF CD4+ [39], SF CD8+ [39], and SF CD4+/CD161+/CD39+ EVs [40]. Conversely, a negative association was observed for RF and SF CD73+/CD39+ EVs [40]. Seropositive RA patients were found to have more CD41+ EVs [26], whereas seronegative had more CD105+ EVs [26]. On the contrary, according to a different study, there was no difference regarding plasmatic EV profile between serological RA phenotypes [29]. Regarding EVs content, low levels of serum exosomal miR-548a-3p were associated with higher levels of RF [44].

SF CD3+, CD4+, and CD8+ EVs did not correlate with ACPA [39]. On the other side, ACPA positive patients had greater levels of SF annexin V+/CD45+ EVs. Moreover, a weak correlation was observed between ACPA titer, CD4+ EVs, and annexin V+/CD45+ EVs [29].

$\mathrm{SF}$ annexin V+ EVs and platelet-derived EVs were increased in RA patients with extra-articular symptoms [29]. Total plasmatic EV number was higher in RA than in patients with cardiovascular risk factors and their concentrations correlated with the number of traditional cardiovascular risk factors [19].

Plasmatic CD14+ and CD62E+ EVs and urinary CD14+ and CD19+ EVs differed between patients in low or high disease activity [57]. Moreover, an association was found between disease activity score on 28 joints (DAS28), plasma, and urine EVs [57].

According to another study, patients with active disease displayed an association between LYmphatic Vessel Endothelial hyaluronic acid receptor-1 (LYVE-1), both in serum and in EVs, and CRP, ACPA titer, and exosomal AA [58].

Many studies, except one [34], reported an interaction between plasmatic EVs or their content- such as miRNAsand plasmatic inflammatory markers (ESR and CRP) [19, 20, 32, 41, 44, 58]. Four papers included tender and swollen joint count in their analysis with different outcomes: plasmatic EVs [19, 23] or SF EVs [40] influenced the joint count. Conversely, in a different study, there was no statistical correlation between plasmatic EVs and joint count [20].

One study highlighted a significant association between plasmatic EVs containing TNF $\alpha$ and disease activity (DAS28 or clinical disease activity index-CDAI) [23]. Several studies detected a positive correlation between DAS28 and plasmatic [19, 20, 34, 41, 57], SF [40] or urinary [57] EVs. This association was not confirmed in other four studies concerning plasmatic EV [41, 54] and SF EVs [39,
40]. Platelet EVs were similar in active and non-active RA patients [34].

\section{Effects of therapy on EVs}

Patients treated with tocilizumab displayed lower levels of plasmatic $\mathrm{CD} 3+\mathrm{CD} 31+$ and $\mathrm{CD} 66 \mathrm{~b}+\mathrm{EVs}$, whereas patients receiving methotrexate had decreased levels of plasmatic CD3+CD31+ EVs [19]. Adversely, another study did not find any difference in plasmatic and urinary EVs levels between treated and untreated subjects [57].

Four studies reported a decrease in either plasmatic EVs $[23,53]$ or urinary EVs [57] after treatment with biological disease-modifying anti-rheumatic drugs (DMARDs) or leukocytapheresis [41], whereas one paper did not report an influence of conventional synthetic (cs)-DMARDs on total plasmatic EVs [32].

A decreased exo-miR-155 expression was found in patients $\mathrm{HCV}$ positive treated with rituximab as compared with subjects treated with anti-TNF $\alpha$ or csDMARDs [52].

Of note, in these studies, RA populations enrolled are extremely heterogenous (e.g. different disease activity and therapies) and, for this reason, caution is needed in drawing conclusions.

\section{Discussion}

We included and reported the results of 41 studies in this systematic review. An overview of the results and a possible role of EVs in RA is reported in Fig. 2.

The total plasmatic EV concentration seems increased in RA when compared with $\mathrm{HC}$, whereas plasmatic EV size was not found dissimilar between the two groups. As already highlighted, some of the studies reporting EV size might not have considered possible shortcomings of methodology. Inconsistency among the included studies could also be explained by the relatively small population enrolled. Moreover, the total plasmatic EV number was found similar in RA and other inflammatory (i.e., SLE, UA, or ReA) and noninflammatory conditions (i.e., OA). Conversely, RA EV concentrations in SF were described at higher levels when compared with HC, OA, and ReA.

The kaleidoscopic effects of EVs on pro-inflammatory pathways, coagulation, and angiogenesis were explored in several studies. Plasmatic EVs subpopulations, based on surface molecules and linked to numerous biological effects (e.g., cell adhesion, immune system, platelet function, vascular system, and hematopoiesis), were found higher in RA than HC, even though this was not confirmed by all studies. Interestingly, in one study, similar results were found only for high disease activity RA. Moreover, different EV subtypes 

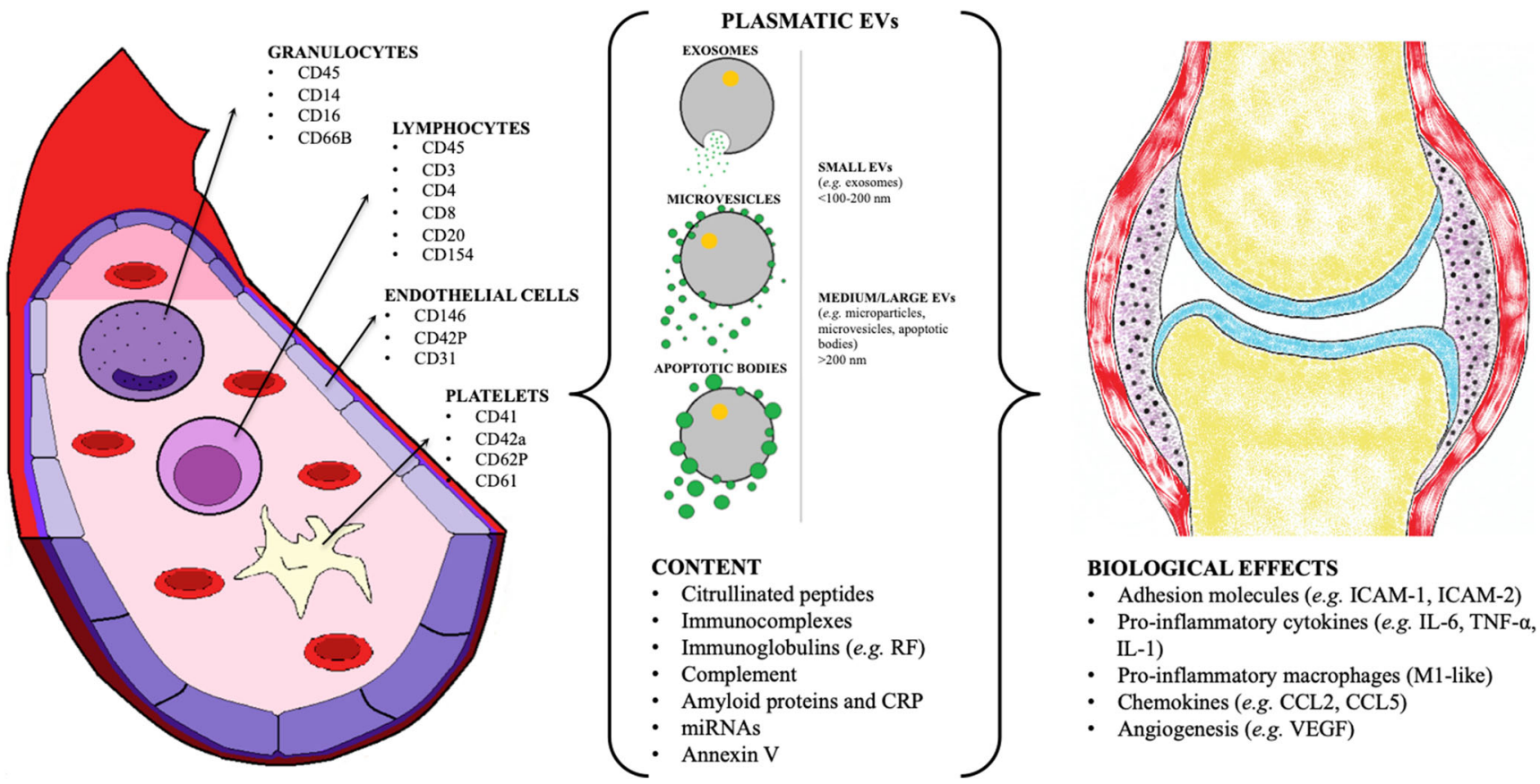

CRP: C-reactive protein; EVs: extracellular vesicles; RF: rheumatoid factor.

Fig. 2 Overview of the possible role of EVs in RA. CRP: C-reactive protein; EVs: extracellular vesicles; RF: rheumatoid factor

were found dissimilar according to disease characteristics, such as disease duration and age at diagnosis. Plasmatic EVs and IC-EVs enhanced inflammatory pathways and cytokines (e.g., IL-6); this was true especially for EVs derived from seropositive and high disease activity patients. Studies investigating whether therapies affect EVs yielded contrasting results. Nevertheless, some in vitro and in vivo evidence could suggest a possible role of inflammatory mediators, targeted by biological therapies (e.g., TNF- $\alpha$ and IL-6), in the pathogenesis mediated by EVs. Despite several studies found a correlation between EVs and disease activity, this could not be confirmed in other ones. The differences observed between $\mathrm{RA}$ and $\mathrm{HC}$ were less marked when RA patients were compared with OA. Moreover, some evidence suggested that EVs containing citrullinated peptides were more abundant in RA than HC but these data were not specific for RA when compared with other arthritides.

Likewise, RA SF showed more abundant EVs derived from immune cells and platelets when compared with OA, but this could not be confirmed with respect to other nonRA inflammatory arthritides.

A limited number of studies, taking into consideration miRNAs, showed that their expression was different in RA versus HC. Furthermore, some data suggested that these differences were not specific for RA since they were not dissimilar from other pathological conditions (e.g., PsA).

EVs seem to enhance the inflammatory process, but their role is not specific for RA. As expected, since RA has the joints as the main target, studies on SF and synovial fibroblasts uncovered differences more specific to RA and, consequently, studies on them are more promising.

Even though a multitude of information could be obtained, definitive conclusions about the role of EVs in RA can difficultly be drawn. Indeed, the analyzed articles varied greatly in methodology and this makes direct comparisons challenging. Moreover, some studies were conducted on small and poorly characterized (e.g., seropositivity, therapy) populations. Various narrative reviews on this topic have been published so far, but they seem to lean excessively on the positive findings partially neglecting the negative ones.

In conclusion, EVs could contribute to better understand RA pathogenesis and they could represent a possible therapeutic target [60]. Moreover, EVs could be of help in the diagnosis (inflammatory vs. non-inflammatory joint diseases), prognosis (e.g., extra-articular involvement) and therapeutic response. Studies focusing on this topic are urged to follow rigorous methodology [10], so that the scientific community can compare them and draw translatable observations.

Supplementary Information The online version contains supplementary material available at https://doi.org/10.1007/s10067-021-05614-w.

Funding Open Access funding provided by Università degli Studi di Milano within the CRUI-CARE Agreement.

Data availability The whole review process has been performed according to PRISMA statements. 


\section{Compliance with ethical standards}

Ethics approval Not applicable.

Consent to participate Not applicable.

Consent for publication Not applicable.

Disclosures None.

Code availability Not applicable.

Open Access This article is licensed under a Creative Commons Attribution 4.0 International License, which permits use, sharing, adaptation, distribution and reproduction in any medium or format, as long as you give appropriate credit to the original author(s) and the source, provide a link to the Creative Commons licence, and indicate if changes were made. The images or other third party material in this article are included in the article's Creative Commons licence, unless indicated otherwise in a credit line to the material. If material is not included in the article's Creative Commons licence and your intended use is not permitted by statutory regulation or exceeds the permitted use, you will need to obtain permission directly from the copyright holder. To view a copy of this licence, visit http://creativecommons.org/licenses/by/4.0/.

\section{References}

1. Smolen JS, Aletaha D, Barton A, Burmester GR, Emery P, Firestein GS, Kavanaugh A, McInnes IB, Solomon DH, Strand V, Yamamoto K (2018) Rheumatoid arthritis. Nat Rev Dis Prim 4: 18001. https://doi.org/10.1038/nrdp.2018.1

2. Smolen JS, Landewe RBM, Bijlsma JWJ, Burmester GR, Dougados M, Kerschbaumer A, McInnes IB, Sepriano A, van Vollenhoven RF, de Wit M, Aletaha D, Aringer M, Askling J, Balsa A, Boers M, den Broeder AA, Buch MH, Buttgereit F, Caporali R, Cardiel MH, De Cock D, Codreanu C, Cutolo M, Edwards CJ, van Eijk-Hustings Y, Emery P, Finckh A, Gossec L, Gottenberg JE, Hetland ML, Huizinga TWJ, Koloumas M, Li Z, Mariette X, Muller-Ladner U, Mysler EF, da Silva JAP, Poor G, Pope JE, Rubbert-Roth A, Ruyssen-Witrand A, Saag KG, Strangfeld A, Takeuchi T, Voshaar M, Westhovens R, van der Heijde D (2020) EULAR recommendations for the management of rheumatoid arthritis with synthetic and biological diseasemodifying antirheumatic drugs: 2019 update. Ann Rheum Dis 79(6):685-699. https://doi.org/10.1136/annrheumdis-2019216655

3. Bykerk VP, Shadick N, Frits M, Bingham CO 3rd, Jeffery I, Iannaccone C, Weinblatt $\mathrm{M}$, Solomon DH (2014) Flares in rheumatoid arthritis: frequency and management. A report from the BRASS registry. J Rheumatol 41(2):227-234. https://doi.org/10. 3899/jrheum.121521

4. Markusse IM, Dirven L, Gerards AH, van Groenendael JH, Ronday HK, Kerstens PJ, Lems WF, Huizinga TW, Allaart CF (2015) Disease flares in rheumatoid arthritis are associated with joint damage progression and disability: 10-year results from the BeSt study. Arthritis Res Ther 17:232. https://doi.org/10.1186/s13075-015$0730-2$

5. MacGregor AJ, Snieder H, Rigby AS, Koskenvuo M, Kaprio J, Aho K, Silman AJ (2000) Characterizing the quantitative genetic contribution to rheumatoid arthritis using data from twins. Arthritis
Rheum 43(1):30-37. https://doi.org/10.1002/1529-0131(200001) 43:1<30::AID-ANR5>3.0.CO;2-B

6. Hwang JY, Randall TD, Silva-Sanchez A (2016) Inducible Bronchus-Associated Lymphoid Tissue: Taming Inflammation in the Lung. Front Immunol 7:258. https://doi.org/10.3389/fimmu. 2016.00258

7. Hart JE, Laden F, Puett RC, Costenbader KH, Karlson EW (2009) Exposure to traffic pollution and increased risk of rheumatoid arthritis. Environ Health Perspect 117(7):1065-1069. https://doi.org/ 10.1289/ehp.0800503

8. Anderson R, Meyer PW, Ally MM, Tikly M (2016) Smoking and Air Pollution as Pro-Inflammatory Triggers for the Development of Rheumatoid Arthritis. Nicotine Tob Res 18(7):1556-1565. https:// doi.org/10.1093/ntr/ntw030

9. Yanez-Mo M, Siljander PR, Andreu Z, Zavec AB, Borras FE, Buzas EI, Buzas K, Casal E, Cappello F, Carvalho J, Colas E, Cordeiro-da Silva A, Fais S, Falcon-Perez JM, Ghobrial IM, Giebel B, Gimona M, Graner M, Gursel I, Gursel M, Heegaard NH, Hendrix A, Kierulf P, Kokubun K, Kosanovic M, Kralj-Iglic V, Kramer-Albers EM, Laitinen S, Lasser C, Lener T, Ligeti E, Line A, Lipps G, Llorente A, Lotvall J, Mancek-Keber M, Marcilla A, Mittelbrunn M, Nazarenko I, Nolte-'t Hoen EN, Nyman TA, O'Driscoll L, Olivan M, Oliveira C, Pallinger E, Del Portillo HA, Reventos J, Rigau M, Rohde E, Sammar M, SanchezMadrid F, Santarem N, Schallmoser K, Ostenfeld MS, Stoorvogel W, Stukelj R, Van der Grein SG, Vasconcelos MH, Wauben MH, De Wever O (2015) Biological properties of extracellular vesicles and their physiological functions. J Extracell Vesicles 4:27066. https://doi.org/10.3402/jev.v4.27066

10. Thery C, Witwer KW, Aikawa E, Alcaraz MJ, Anderson JD, Andriantsitohaina R, Antoniou A, Arab T, Archer F, Atkin-Smith GK, Ayre DC, Bach JM, Bachurski D, Baharvand H, Balaj L, Baldacchino S, Bauer NN, Baxter AA, Bebawy M, Beckham C, Bedina Zavec A, Benmoussa A, Berardi AC, Bergese P, Bielska E, Blenkiron C, Bobis-Wozowicz S, Boilard E, Boireau W, Bongiovanni A, Borras FE, Bosch S, Boulanger CM, Breakefield X, Breglio AM, Brennan MA, Brigstock DR, Brisson A, Broekman ML, Bromberg JF, Bryl-Gorecka P, Buch S, Buck AH, Burger D, Busatto S, Buschmann D, Bussolati B, Buzas EI, Byrd JB, Camussi G, Carter DR, Caruso S, Chamley LW, Chang YT, Chen C, Chen S, Cheng L, Chin AR, Clayton A, Clerici SP, Cocks A, Cocucci E, Coffey RJ, Cordeiro-da-Silva A, Couch Y, Coumans FA, Coyle B, Crescitelli R, Criado MF, D'Souza-Schorey C, Das S, Datta Chaudhuri A, de Candia P, De Santana EF, De Wever O, Del Portillo HA, Demaret T, Deville S, Devitt A, Dhondt B, Di Vizio D, Dieterich LC, Dolo V, Dominguez Rubio AP, Dominici M, Dourado MR, Driedonks TA, Duarte FV, Duncan HM, Eichenberger RM, Ekstrom K, El Andaloussi S, Elie-Caille C, Erdbrugger U, Falcon-Perez JM, Fatima F, Fish JE, FloresBellver M, Forsonits A, Frelet-Barrand A, Fricke F, Fuhrmann G, Gabrielsson S, Gamez-Valero A, Gardiner C, Gartner K, Gaudin R, Gho YS, Giebel B, Gilbert C, Gimona M, Giusti I, Goberdhan DC, Gorgens A, Gorski SM, Greening DW, Gross JC, Gualerzi A, Gupta GN, Gustafson D, Handberg A, Haraszti RA, Harrison P, Hegyesi H, Hendrix A, Hill AF, Hochberg FH, Hoffmann KF, Holder B, Holthofer H, Hosseinkhani B, Hu G, Huang Y, Huber V, Hunt S, Ibrahim AG, Ikezu T, Inal JM, Isin M, Ivanova A, Jackson HK, Jacobsen S, Jay SM, Jayachandran M, Jenster G, Jiang L, Johnson SM, Jones JC, Jong A, Jovanovic-Talisman T, Jung S, Kalluri R, Kano SI, Kaur S, Kawamura Y, Keller ET, Khamari D, Khomyakova E, Khvorova A, Kierulf P, Kim KP, Kislinger T, Klingeborn M, Klinke DJ 2nd, Kornek M, Kosanovic MM, Kovacs AF, Kramer-Albers EM, Krasemann S, Krause M, Kurochkin IV, Kusuma GD, Kuypers S, Laitinen S, Langevin SM, Languino LR, Lannigan J, Lasser C, Laurent LC, Lavieu G, Lazaro-Ibanez E, Le Lay S, Lee MS, YXF L, Lemos DS, 
Lenassi M, Leszczynska A, Li IT, Liao K, Libregts SF, Ligeti E, Lim R, Lim SK, Line A, Linnemannstons K, Llorente A, Lombard CA, Lorenowicz MJ, Lorincz AM, Lotvall J, Lovett J, Lowry MC, Loyer X, Lu Q, Lukomska B, Lunavat TR, Maas SL, Malhi H, Marcilla A, Mariani J, Mariscal J, Martens-Uzunova ES, MartinJaular L, Martinez MC, Martins VR, Mathieu M, Mathivanan S, Maugeri M, McGinnis LK, McVey MJ, Meckes DG Jr, Meehan KL, Mertens I, Minciacchi VR, Moller A, Moller Jorgensen M, Morales-Kastresana A, Morhayim J, Mullier F, Muraca M, Musante L, Mussack V, Muth DC, Myburgh KH, Najrana T, Nawaz M, Nazarenko I, Nejsum P, Neri C, Neri T, Nieuwland R, Nimrichter L, Nolan JP, Nolte-'t Hoen EN, Noren Hooten N, O'Driscoll L, O'Grady T, O'Loghlen A, Ochiya T, Olivier M, Ortiz A, Ortiz LA, Osteikoetxea X, Ostergaard O, Ostrowski M, Park J, Pegtel DM, Peinado H, Perut F, Pfaffl MW, Phinney DG, Pieters BC, Pink RC, Pisetsky DS, Pogge von Strandmann E, Polakovicova I, Poon IK, Powell BH, Prada I, Pulliam L, Quesenberry P, Radeghieri A, Raffai RL, Raimondo S, Rak J, Ramirez MI, Raposo G, Rayyan MS, Regev-Rudzki N, Ricklefs FL, Robbins PD, Roberts DD, Rodrigues SC, Rohde E, Rome S, Rouschop KM, Rughetti A, Russell AE, Saa P, Sahoo S, SalasHuenuleo E, Sanchez C, Saugstad JA, Saul MJ, Schiffelers RM, Schneider R, Schoyen TH, Scott A, Shahaj E, Sharma S, Shatnyeva O, Shekari F, Shelke GV, Shetty AK, Shiba K, Siljander PR, Silva AM, Skowronek A, Snyder OL 2nd, Soares RP, Sodar BW, Soekmadji C, Sotillo J, Stahl PD, Stoorvogel W, Stott SL, Strasser EF, Swift S, Tahara H, Tewari M, Timms K, Tiwari S, Tixeira R, Tkach M, Toh WS, Tomasini R, Torrecilhas AC, Tosar JP, Toxavidis V, Urbanelli L, Vader P, van Balkom BW, van der Grein SG, Van Deun J, van Herwijnen MJ, Van KeurenJensen K, van Niel G, van Royen ME, van Wijnen AJ, Vasconcelos MH, Vechetti IJ Jr, Veit TD, Vella LJ, Velot E, Verweij FJ, Vestad B, Vinas JL, Visnovitz T, Vukman KV, Wahlgren J, Watson DC, Wauben MH, Weaver A, Webber JP, Weber V, Wehman AM, Weiss DJ, Welsh JA, Wendt S, Wheelock AM, Wiener Z, Witte L, Wolfram J, Xagorari A, Xander P, Xu J, Yan X, Yanez-Mo M, Yin H, Yuana Y, Zappulli V, Zarubova J, Zekas V, Zhang JY, Zhao Z, Zheng L, Zheutlin AR, Zickler AM, Zimmermann P, Zivkovic AM, Zocco D, Zuba-Surma EK (2018) Minimal information for studies of extracellular vesicles 2018 (MISEV2018): a position statement of the International Society for Extracellular Vesicles and update of the MISEV2014 guidelines. J Extracell Vesicles 7(1):1535750. https://doi.org/10.1080/20013078.2018.1535750

11. Skog J, Wurdinger T, van Rijn S, Meijer DH, Gainche L, SenaEsteves M, Curry WT Jr, Carter BS, Krichevsky AM, Breakefield XO (2008) Glioblastoma microvesicles transport RNA and proteins that promote tumour growth and provide diagnostic biomarkers. Nat Cell Biol 10(12):1470-1476. https://doi.org/10.1038/ncb1800

12. Fu H, Hu D, Zhang L, Tang P (2018) Role of extracellular vesicles in rheumatoid arthritis. Mol Immunol 93:125-132. https://doi.org/ 10.1016/j.molimm.2017.11.016

13. Li Z, Wang Y, Xiao K, Xiang S, Li Z, Weng X (2018) Emerging Role of Exosomes in the Joint Diseases. Cell Physiol Biochem 47(5):2008-2017. https://doi.org/10.1159/000491469

14. Krajewska-Wlodarczyk M, Owczarczyk-Saczonek A, Zuber Z, Wojtkiewicz M, Wojtkiewicz J (2019) Role of Microparticles in the Pathogenesis of Inflammatory Joint Diseases. Int J Mol Sci 20(21). https://doi.org/10.3390/ijms20215453

15. Tavasolian F, Moghaddam AS, Rohani F, Abdollahi E, Janzamin E, Momtazi-Borojeni AA, Moallem SA, Jamialahmadi T, Sahebkar A (2020) Exosomes: Effectual players in rheumatoid arthritis. Autoimmun Rev 19(6):102511. https://doi.org/10.1016/j.autrev. 2020.102511

16. Moher D, Shamseer L, Clarke M, Ghersi D, Liberati A, Petticrew M, Shekelle P, Stewart LA, Group P-P (2015) Preferred reporting items for systematic review and meta-analysis protocols (PRISMA-
P) 2015 statement. Syst Rev 4:1. https://doi.org/10.1186/20464053-4-1

17. Liberati A, Altman DG, Tetzlaff J, Mulrow C, Gotzsche PC, Ioannidis JP, Clarke M, Devereaux PJ, Kleijnen J, Moher D (2009) The PRISMA statement for reporting systematic reviews and meta-analyses of studies that evaluate health care interventions: explanation and elaboration. Ann Intern Med 151(4):W65-W94. https://doi.org/10.7326/0003-4819-151-4-200908180-00136

18. Schioppo T, Ubiali T, Ingegnoli F (2020) The role of extracellular vesicles in rheumatoid arthritis: a systematic review. PROSPERO: International prospective register of systematic reviews CRD42020181164

19. Rodríguez-Carrio J, Alperi-López M, López P, Alonso-Castro S, Carro-Esteban SR, Ballina-García FJ, Suárez A (2015) Altered profile of circulating microparticles in rheumatoid arthritis patients. Clin Sci 128(7):437-448. https://doi.org/10.1042/CS20140675

20. Arntz OJ, Pieters BCH, Thurlings RM, Wenink MH, van Lent PLEM, Koenders MI, van den Hoogen FHJ, van der Kraan PM, van de Loo FAJ (2018) Rheumatoid Arthritis Patients With Circulating Extracellular Vesicles Positive for IgM Rheumatoid Factor Have Higher Disease Activity. Front Immunol 9:2388. https://doi.org/10.3389/fimmu.2018.02388

21. Skriner K, Adolph K, Jungblut PR, Burmester GR (2006) Association of citrullinated proteins with synovial exosomes. and. Rheumatism 54(12):3809-3814. https://doi.org/10.1002/art.22276

22. Atehortúa L, Rojas M, Vásquez G, Muñoz-Vahos CH, VanegasGarcía A, Posada-Duque RA, Castaño D (2019) Endothelial activation and injury by microparticles in patients with systemic lupus erythematosus and rheumatoid arthritis. Res Ther 21(1):34. https:// doi.org/10.1186/s13075-018-1796-4

23. Barbati C, Vomero M, Colasanti T, Diociaiuti M, Ceccarelli F, Ferrigno S, Finucci A, Miranda F, Novelli L, Perricone C, Spinelli FR, Truglia S, Conti F, Valesini G, Alessandri C (2018) $\mathrm{TNF} \alpha$ expressed on the surface of microparticles modulates endothelial cell fate in rheumatoid arthritis. Res Ther 20(1):273. https:// doi.org/10.1186/s13075-018-1768-8

24. Biró É, Nieuwland R, Tak PP, Pronk LM, Schaap MCL, Sturk A, Hack CE (2007) Activated complement components and complement activator molecules on the surface of cell-derived microparticles in patients with rheumatoid arthritis and healthy individuals. Ann Rheum Dis 66(8):1085-1092. https://doi.org/10.1136/ard. 2006.061309

25. Boilard E, Nigrovic PA, Larabee K, Watts GFM, Coblyn JS, Weinblatt ME, Massarotti EM, Remold-O'Donnell E, Farndale RW, Ware J, Lee DM (2010) Platelets amplify inflammation in arthritis via collagen-dependent microparticle production. Science 327(5965):580-583. https://doi.org/10.1126/science.1181928

26. Burbano C, Rojas M, Muñoz-Vahos C, Vanegas-García A, Correa LA, Vásquez G, Castaño D (2018) Extracellular vesicles are associated with the systemic inflammation of patients with seropositive rheumatoid arthritis. Sci Rep 8(1):17917. https://doi.org/10.1038/ s41598-018-36335-x

27. Burbano C, Villar-Vesga J, Vásquez G, Muñoz-Vahos C, Rojas M, Castaño D (2019) Proinflammatory differentiation of macrophages through microparticles that form immune complexes leads to $\mathrm{T}$-and B-cell activation in systemic autoimmune diseases. Front Immunol 10(AUG). https://doi.org/10.3389/fimmu.2019.02058

28. Berckmans RJ, Nieuwland R, Tak PP, Böing AN, Romijn FPHTM, Kraan MC, Breedveld FC, Hack CE, Sturk A (2002) Cell-derived microparticles in synovial fluid from inflamed arthritic joints support coagulation exclusively via a factor VII-dependent mechanism. and. Rheumatism 46(11):2857-2866. https://doi.org/10.1002/art. 10587

29. Michael BNR, Kommoju V, Kavadichanda Ganapathy C, Negi VS (2019) Characterization of cell-derived microparticles in synovial 
fluid and plasma of patients with rheumatoid arthritis. Rheumatol Int 39(8):1377-1387. https://doi.org/10.1007/s00296-019-04337-1

30. Chen Z, Wang H, Xia Y, Yan F, Lu Y (2018) Therapeutic potential of mesenchymal cell-derived miRNA-150-5p-expressing exosomes in rheumatoid arthritis mediated by the modulation of MMP14 and VEGF. J Immunol 201(8):2472-2482. https://doi.org/10.4049/ jimmunol.1800304

31. Wang L, Wang C, Jia X, Yu J (2018) Circulating exosomal miR-17 inhibits the induction of regulatory $\mathrm{T}$ cells via suppressing TGFBR II expression in rheumatoid arthritis. Physiol Biochem 50(5):17541763. https://doi.org/10.1159/000494793

32. Van Eijk IC, Tushuizen ME, Sturk A, Dijkmans BAC, Boers M, Voskuyl AE, Diamant M, Wolbink GJ, Nieuwland R, Nurmohamed MT (2010) Circulating microparticles remain associated with complement activation despite intensive antiinflammatory therapy in early rheumatoid arthritis. Ann Rheum Dis 69(7):1378-1382. https://doi.org/10.1136/ard.2009.118372

33. Cloutier N, Tan S, Boudreau LH, Cramb C, Subbaiah R, Lahey L, Albert A, Shnayder R, Gobezie R, Nigrovic PA, Farndale RW, Robinson WH, Brisson A, Lee DM, Boilard E (2013) The exposure of autoantigens by microparticles underlies the formation of potent inflammatory components: The microparticle-associated immune complexes. EMBO Mol Med 5(2):235-249. https://doi.org/10. 1002/emmm.201201846

34. Knijff-Dutmer EAJ, Koerts J, Nieuwland R, Kalsbeek-Batenburg EM, Van De Laar MAFJ (2002) Elevated levels of platelet microparticles are associated with disease activity in rheumatoid arthritis. and. Rheumatism 46(6):1498-1503. https://doi.org/10.1002/art. 10312

35. Xu D, Song M, Chai C, Wang J, Jin C, Wang X, Cheng M, Yan S (2019) Exosome-encapsulated miR-6089 regulates inflammatory response via targeting TLR4. J Physiol 234(2):1502-1511. https:// doi.org/10.1002/jcp.27014

36. Marton N, Kovács OT, Baricza E, Kittel Á, Győri D, Mócsai A, Meier FMP, Goodyear CS, McInnes IB, Buzás EI, Nagy G (2017) Extracellular vesicles regulate the human osteoclastogenesis: divergent roles in discrete inflammatory arthropathies. and. Mol Life Sci 74(19):3599-3611. https://doi.org/10.1007/s00018-017-2535-8

37. Gitz E, Pollitt AY, Gitz-Francois JJ, Alshehri O, Mori J, Montague S, Nash GB, Douglas MR, Gardiner EE, Andrews RK, Buckley CD, Harrison P, Watson SP (2014) CLEC-2 expression is maintained on activated platelets and on platelet microparticles. Blood 124(14):2262-2270. https://doi.org/10.1182/blood-2014-05572818

38. Greisen SR, Yan Y, Hansen AS, Venø MT, Nyengaard JR, Moestrup SK, Hvid M, Freeman GJ, Kjems J, Deleuran B (2017) Extracellular vesicles transfer the receptor programmed death-1 in rheumatoid arthritis. Front Immunol 8(JUL). https://doi.org/10. 3389/fimmu.2017.00851

39. György B, Szabó TG, Turiák L, Wright M, Herczeg P, Lédeczi Z, Kittel Á, Polgár A, Tóth K, Dérfalvi B, Zelenák G, Böröcz I, Carr B, Nagy G, Vékey K, Gay S, Falus A, Buzás EI (2012) Improved Flow Cytometric Assessment Reveals Distinct Microvesicle (CellDerived Microparticle) Signatures in Joint Diseases. PLoS ONE 7(11):e49726. https://doi.org/10.1371/journal.pone.0049726

40. Fan W, Wang W, Wu J, Ma L, Guo J (2017) Identification of CD4+ T-cell-derived CD161+ CD39+ and CD39+CD73+ microparticles as new biomarkers for rheumatoid arthritis. Biomark Med 11(2): 107-116. https://doi.org/10.2217/bmm-2016-0261

41. Umekita K, Hidaka T, Ueno S, Takajo I, Kai Y, Nagatomo Y, Sawaguchi A, Suganuma T, Okayama A (2009) Leukocytapheresis (LCAP) decreases the level of platelet-derived microparticles (MPs) and increases the level of granulocytesderived MPs: A possible connection with the effect of LCAP on rheumatoid arthritis. Mod Rheumatol 19(3):265-272. https://doi. org/10.1007/s10165-009-0164-2
42. Messer L, Alsaleh G, Freyssinet JM, Zobairi F, Leray I, Gottenberg JE, Sibilia J, Toti-Orfanoudakis F, Wachsmann D (2009) Microparticle-induced release of B-lymphocyte regulators by rheumatoid synoviocytes. Res Ther 11(2):R40. https://doi.org/10.1186/ $\operatorname{ar} 2648$

43. Jüngel A, Distler O, Schulze-Horsel U, Huber LC, Ha HR, Simmen B, Kalden JR, Pisetsky DS, Gay S, Distler JHW (2007) Microparticles stimulate the synthesis of prostaglandin E(2) via induction of cyclooxygenase 2 and microsomal prostaglandin $\mathrm{E}$ synthase 1. Arthritis Rheum 56(11):3564-3574. https://doi.org/10. 1002/art.22980

44. Wang Y, Zheng F, Gao G, Yan S, Zhang L, Wang L, Cai X, Wang $\mathrm{X}, \mathrm{Xu} \mathrm{D}$, Wang J (2018) MiR-548a-3p regulates inflammatory response via TLR4/NF- $\mathrm{kB}$ signaling pathway in rheumatoid arthritis. J Cell Biochem. https://doi.org/10.1002/jcb.26659

45. Szabó-Taylor KÉ, Tóth EÁ, Balogh AM, Sódar BW, Kádár L, Pálóczi K, Fekete N, Németh A, Osteikoetxea X, Vukman KV, Holub M, Pállinger É, Nagy G, Winyard PG, Buzás EI (2017) Monocyte activation drives preservation of membrane thiols by promoting release of oxidised membrane moieties via extracellular vesicles. Free Radic Biol Med 108:56-65. https://doi.org/10.1016/j. freeradbiomed.2017.03.016

46. Headland SE, Jones HR, Norling LV, Kim A, Souza PR, Corsiero E, Gil CD, Nerviani A, Dell'accio F, Pitzalis C, Oliani SM, Jan LY, Perretti M (2015) Neutrophil-derived microvesicles enter cartilage and protect the joint in inflammatory arthritis. Sci Transl Med 7(315):315ra190. https://doi.org/10.1126/scitranslmed.aac5608

47. Chen X-M, Zhao Y, Wu X-D, Wang M-J, Yu H, Lu J-J, Hu Y-J, Huang Q-C, Huang R-Y, Lu C-J (2019) Novel findings from determination of common expressed plasma exosomal microRNAs in patients with psoriatic arthritis, psoriasis vulgaris, rheumatoid arthritis, and gouty arthritis. Discov Med 28(151):47-68

48. Oba R, Isomura M, Igarashi A, Nagata K (2019) Circulating CD3+ HLA-DR+extracellular vesicles as a marker for Th1/Tc1-Type immune responses. J Immunol Res 2019:1-13. https://doi.org/10. $1155 / 2019 / 6720819$

49. Villar-Vesga J, Grajales C, Burbano C, Vanegas-García A, MuñozVahos CH, Vásquez G, Rojas M, Castaño D (2019) Platelet-derived microparticles generated in vitro resemble circulating vesicles of patients with rheumatoid arthritis and activate monocytes. Immunology 336:1-11. https://doi.org/10.1016/j.cellimm.2018. 12.002

50. Reich N, Beyer C, Gelse K, Akhmetshina A, Dees C, Zwerina J, Schett G, Distler O, Distler JHW (2011) Microparticles stimulate angiogenesis by inducing $\operatorname{ELR}(+)$ CXC-chemokines in synovial fibroblasts. J Cell Mol Med 15(4):756-762. https://doi.org/10. 1111/j.1582-4934.2010.01051.x

51. Michael BNR, Misra DP, Chengappa KG, Negi VS (2018) Relevance of elevated microparticles in peripheral blood and synovial fluid of patients with rheumatoid arthritis. Indian J Rheumatol 13(4):222-226. https://doi.org/10.4103/injr.injr_101_18

52. Liao TL, Hsieh SL, Chen YM, Chen HH, Liu HJ, Lee HC, Chen DY (2018) Rituximab May Cause Increased Hepatitis C Virus Viremia in Rheumatoid Arthritis Patients Through Declining Exosomal MicroRNA-155. and. Rheumatology 70(8):1209-1219. https://doi.org/10.1002/art.40495

53. Rodríguez-Carrio J, Alperi-López M, López P, Ballina-García FJ, Suárez A (2015) Good response to tumour necrosis factor alpha blockade results in an angiogenic $\mathrm{T}$ cell recovery in rheumatoid arthritis patients. Rheumatology (United Kingdom) 54(6):1129 1131. https://doi.org/10.1093/rheumatology/kev025

54. Sellam J, Proulle V, Jüngel A, Ittah M, Miceli Richard C, Gottenberg J-E, Toti F, Benessiano J, Gay S, Freyssinet J-M, Mariette X (2009) Increased levels of circulating microparticles in primary Sjögren's syndrome, systemic lupus erythematosus and 
rheumatoid arthritis and relation with disease activity. Arthritis Res Ther 11(5):R156-R156. https://doi.org/10.1186/ar2833

55. Berckmans RJ, Nieuwland R, Kraan MC, Schaap MC, Pots D, Smeets TJ, Sturk A, Tak PP (2005) Synovial microparticles from arthritic patients modulate chemokine and cytokine release by synoviocytes. Res Ther 7(3):R536-R544

56. Tsuno H, Arito M, Suematsu N, Sato T, Hashimoto A, Matsui T, Omoteyama K, Sato M, Okamoto K, Tohma S, Kurokawa MS, Kato T (2018) A proteomic analysis of serum-derived exosomes in rheumatoid arthritis. BMC Rheumatol 2:35-35. https://doi.org/ 10.1186/s41927-018-0041-8

57. Viñuela-Berni V, Doníz-Padilla L, Figueroa-Vega N, PortilloSalazar H, Abud-Mendoza C, Baranda L, González-Amaro R (2015) Proportions of several types of plasma and urine microparticles are increased in patients with rheumatoid arthritis with active disease. Clin Exp Immunol 180(3):442-451. https://doi.org/10. $1111 /$ cei. 12598
58. Yoo J, Lee SK, Lim M, Sheen D, Choi E-H, Kim SA (2017) Exosomal amyloid A and lymphatic vessel endothelial hyaluronic acid receptor-1 proteins are associated with disease activity in rheumatoid arthritis. Arthritis Res Ther 19(1):119-119. https://doi.org/ 10.1186/s13075-017-1334-9

59. Zhang H-G, Liu C, Su K, Yu S, Zhang L, Zhang S, Wang J, Cao X, Grizzle W, Kimberly RP (2006) A membrane form of TNF-alpha presented by exosomes delays $\mathrm{T}$ cell activation-induced cell death. $\mathrm{J}$ Immunol 176(12):7385-7393. https://doi.org/10.4049/jimmunol. 176.12.7385

60. Tofino-Vian M, Guillen MI, Alcaraz MJ (2018) Extracellular vesicles: A new therapeutic strategy for joint conditions. Biochem Pharmacol 153:134-146. https://doi.org/10.1016/j.bcp.2018.02. 004

Publisher's note Springer Nature remains neutral with regard to jurisdictional claims in published maps and institutional affiliations. 